\title{
Nigral Glutamatergic Neurons Control the Speed of Locomotion
}

\author{
Dimitri Ryczko, ${ }^{1,2}$ Swantje Grätsch, ${ }^{1,3}$ Laura Schläger, ${ }^{1}$ Avo Keuyalian, ${ }^{1}$ Zakaria Boukhatem, ${ }^{1}$ Claudia Garcia, ${ }^{1}$ \\ François Auclair, ${ }^{1}$ Ansgar Büschges, ${ }^{3}$ and Réjean Dubuc ${ }^{1,4}$ \\ ${ }^{1}$ Groupe de Recherche sur le Système Nerveux Central, Département de Neurosciences, Université de Montréal, Montréal, Québec H3C 3J7, Canada, \\ 2Département de Pharmacologie-Physiologie, Université de Sherbrooke, Sherbrooke, Québec J1H 5N4, Canada, ${ }^{3}$ Department of Animal Physiology, \\ Biocenter Cologne, University of Cologne, 50674 Cologne, Germany, and ${ }^{4}$ Groupe de Recherche en Activité Physique Adaptée, Département des Sciences de \\ l'Activité Physique, Université du Québec à Montréal, Montréal, Québec, H3C 3P8, Canada
}

The mesencephalic locomotor region (MLR) plays a crucial role in locomotor control. In vertebrates, stimulation of the MLR at increasing intensities elicits locomotion of growing speed. This effect has been presumed to result from higher brain inputs activating the MLR like a dimmer switch. Here, we show in lampreys (Petromyzon marinus) of either sex that incremental stimulation of a region homologous to the mammalian substantia nigra pars compacta $(\mathrm{SNc})$ evokes increasing activation of MLR cells with a graded increase in the frequency of locomotor movements. Neurons co-storing glutamate and dopamine were found to project from the primal SNc to the MLR. Blockade of glutamatergic transmission largely diminished MLR cell responses and locomotion. Local blockade of $D_{1}$ receptors in the MLR decreased locomotor frequency, but did not disrupt the SNc-evoked graded control of locomotion. Our findings revealed the presence of a glutamatergic input to the MLR originating from the primal SNc that evokes graded locomotor movements.

Key words: dopamine; glutamate; lamprey; locomotion; mesencephalic locomotor region; substantia nigra pars compacta

\section{Significance Statement}

The mesencephalic locomotor region (MLR) plays a crucial role in the control of locomotion. It projects downward to reticulospinal neurons that in turn activate the spinal locomotor networks. Increasing the intensity of MLR stimulation produces a growing activation of reticulospinal cells and a progressive increase in the speed of locomotor movements. Since the discovery of the MLR some 50 years ago, it has been presumed that higher brain regions activate the MLR in a graded fashion, but this has not been confirmed yet. Here, using a combination of techniques from cell to behavior, we provide evidence of a new glutamatergic pathway activating the MLR in a graded fashion, and consequently evoking a progressive increase in locomotor output.

\section{Introduction}

In the brainstem, the mesencephalic locomotor region (MLR) plays a crucial role in locomotor control. First discovered in cats by a Russian team (Shik et al., 1966), the MLR was found in all vertebrates tested afterward (lamprey: Sirota et al., 2000; sala-

Received June 28, 2017; revised Aug. 8, 2017; accepted Aug. 26, 2017.

Author contributions: D.R., S.G., F.A., and R.D. designed research; D.R., S.G., L.S., A.K., Z.B., C.G., and F.A. performed research; D.R., S.G., L.S., A.K., Z.B., C.G., F.A., A.B., and R.D. analyzed data; D.R., A.B., and R.D. wrote the paper.

This work was supported by the Canadian Institutes of Health Research (15129); the Fonds de la Recherche en Santé du Québec (Groupe de Recherche sur le Système Nerveux Central, GRSNC, 5249); the Natural Sciences and Engineering Research Council of Canada Grant 217435 (R.D.); the Great Lakes Fishery Commission Grants 54011 and 54021 (R.D.); fellowships from the Fonds de la Recherche en Santé du Québec (D.R.) and the GRSNC Jasper fellowship (D.R.); and scholarships from the University of Cologne and the German Academic Exchange Service (S.G.). We thank Arlette Kolta for providing access to her electrophysiology setup for some experiments, Danielle Veilleux for her technical assistance, and Frédéric Bernard for his help with the graphics.

The authors declare no competing financial interests.

Correspondence should be addressed to Dr. Réjean Dubuc, Groupe de Recherche en Activité Physique Adaptée, Département des Sciences de l'Activité Physique, Université du Québec à Montréal, C.P. 8888, Section Centre-ville, Montréal, QC H3C 3P8, Canada. E-mail: rejean.dubuc@gmail.com.

DOI:10.1523/JNEUROSCI.1810-17.2017

Copyright $\odot 2017$ the authors $\quad 0270-6474 / 17 / 379759-12 \$ 15.00 / 0$ mander: Cabelguen et al., 2003; stingray: Bernau et al., 1991; bird: Sholomenko et al., 1991; rat: Garcia-Rill et al., 1987; mouse: Lee et al., 2014; Roseberry et al., 2016; rabbit: Musienko et al., 2008; guinea-pig: Marlinsky and Voitenko, 1991; monkey: Eidelberg et al., 1981; Karachi et al., 2010; Goetz et al., 2016). The MLR projects downward to reticulospinal neurons, which activate the spinal locomotor networks (cat: Orlovskiŭ, 1970; Steeves and Jordan, 1980; Garcia-Rill and Skinner, 1987a,b; Noga et al., 1991; Musienko et al., 2012; rat: Bachmann et al., 2013; bird: Sholomenko et al., 1991; lamprey: Buchanan and Grillner, 1987; Brocard et al., 2010; mouse: Bretzner and Brownstone, 2013; salamander: Ryczko et al., 2016a). One salient feature of the MLR lies in its ability to finely control locomotor output. Increasing MLR stimulation intensity produces a growing activation of reticulospinal cells and a progressive increase in the speed of locomotor movements.

Since the discovery of the MLR (Shik et al., 1966), it was presumed that the MLR is activated incrementally (i.e., like a dimmer switch) by higher brain regions, but the source of the rheostat-like inputs remained unknown. The MLR receives projections from the cortex, basal ganglia, periaqueductal gray, lat- 
eral hypothalamus (for review, see Ryczko and Dubuc, 2013), and from dopamine neurons of the substantia nigra pars compacta (SNc; Ryczko et al., 2013, 2016b). The physiological role of these different inputs to the MLR is not fully understood. The tonic inhibition sent by the output stations of the basal ganglia (lamprey: Stephenson-Jones et al., 2011, 2012; Ménard et al., 2007; cat: Takakusaki et al., 2003; mouse: Kravitz et al., 2010; Roseberry et al., 2016) is considered to be involved in action selection and therefore locomotion initiation or suppression, rather than fine control of locomotion (Albin et al., 1989; Redgrave et al., 1999; Grillner et al., 2013; Grillner and Robertson, 2016). The lamprey homolog of the mammalian motor cortex (i.e., pallium) was shown to elicit reticulospinal responses and locomotion (Ocaña et al., 2015), but its contribution to the graded control of MLR activity and locomotion is unknown.

So far, only one source of input to the MLR called the posterior tuberculum (PT) was characterized physiologically. This diencephalic region, which is considered homologous to the mammalian SNc (Pombal et al., 1997; Stephenson-Jones et al., 2011; Ryczko et al., 2013, 2016b), provides a strong excitatory input to MLR cells and robustly evokes locomotion (Derjean et al., 2010; Gariépy et al., 2012a; Ryczko et al., 2013). The PT sends a descending dopaminergic projection to the MLR (Ryczko et al., 2013; Pérez-Fernández et al., 2014) where it releases dopamine that increases locomotor output through a $\mathrm{D}_{1}$ receptor-dependent mechanism (Ryczko et al., 2013). Interestingly, the PT also contains glutamatergic neurons (Villar-Cerviño et al., 2011, 2013), and data suggest that their descending projections could control MLR activity. The PT sends non-dopaminergic (thus potentially glutamatergic) projections to the MLR (Ryczko et al., 2013). PT stimulation elicits fast synaptic responses in MLR cells (Gariépy et al., 2012a; Ryczko et al., 2013). Blockade of MLR glutamatergic receptors disrupts reticulospinal responses elicited by stimulation of the olfactory bulbs, which project to the PT (Derjean et al., 2010). Glutamate application in the MLR elicits locomotion (Brocard et al., 2010; Gariépy et al., 2012a). However, there is no direct evidence for descending glutamatergic inputs from the PT to the MLR, and it is unknown whether such input can progressively increase MLR activation and the speed of the locomotor movements. Here, using neural tracing, immunofluorescence, calcium imaging, patch-clamp recordings, and intracellular recordings during locomotion in lampreys, we show that a descending glutamatergic pathway originating from the primal SNc controls MLR activity and locomotor movements like a dimmer switch.

\section{Materials and Methods}

Ethics statement. All procedures conformed to the guidelines of the Canadian Council on Animal Care and were approved by the animal care and use committees of the Université de Montréal (Quebec, Canada) and Université du Québec à Montréal (Quebec, Canada). A total of 47 sea lampreys (Petromyzon marinus) were used, with $n=36$ larvae for physiology experiments and $n=4$ transformed and $n=7$ adults for anatomy experiments. Sex of the individuals used was not taken into account in the present study. Care was taken to minimize the number of animals used and their suffering.

Semi-intact and isolated brain preparations. Larval sea lampreys were anesthetized with tricaine methanesulphonate (MS 222, 200 mg/L; SigmaAldrich) dissolved in a Ringer's solution (in mM: $130 \mathrm{NaCl}, 2.1 \mathrm{KCl}, 2.6$ $\mathrm{CaCl}_{2}, 1.8 \mathrm{MgCl}_{2}, 4.0$ HEPES, 4.0 dextrose, and $1.0 \mathrm{NaHCO}_{3}$ at $\mathrm{pH} 7.4$ ). The animals were anesthetized for $8-10 \mathrm{~min}$ and then transferred into oxygenated cold Ringer's solution. To expose the brain, the skin and muscles were removed from the rostral part of the animal. The dorsal cranium was opened to obtain ad libitum access to the PT and to reticulospinal neurons in the middle rhombencephalic reticular nucleus
(MRRN). Brain tissue rostral to the PT was removed by a transverse section between the diencephalon and the telencephalon. The rostral spinal segments were exposed and the caudal body parts were left intact. The brain was pinned down dorsal side up in the recording chamber, and the body was free to move in a video monitored chamber. To provide access to the PT, a dorsal midsagittal transection was performed at the level of the diencephalon. Recovery time lasted $1 \mathrm{~h}$ before the recording experiments began. For isolated brain preparations, the same dissection procedure was used, but the body was removed.

Electrophysiology and stimulation. Intracellular recordings were performed with sharp glass microelectrodes $(80-110 \mathrm{M} \Omega$ ) filled with potassium acetate $(4 \mathrm{M})$. The signals were amplified with an Axoclamp 2A (Molecular Devices). Only cells with a membrane potential $<-60 \mathrm{mV}$ and held stable for $15 \mathrm{~min}$ after impalement were included in the study.

Extracellular recordings of reticulospinal neurons were performed using glass micropipettes (diameter $5 \mu \mathrm{m}$ ) filled with Ringer's solution and the recordings were amplified with a model 1800 amplifier (bandwidth $100-500 \mathrm{~Hz}$; A-M Systems). Signals were acquired (sampling rate of $5-10 \mathrm{kHz}$ ) through a Digidata 1200 series interface coupled with Clampex 9.0 (Brocard et al., 2010; Ryczko et al., 2013).

Targeted patch-clamp recordings of MLR cells were done using the protocol previously developed in the laboratory (Gariépy et al., 2012a; Ryczko et al., 2013). Briefly, MLR cells were first retrogradely labeled in vivo from an injection of Texas Red dextran amines (MW 3000 Da; Invitrogen) in the MRRN. The following day, the animal was killed and the brain was isolated and placed in a cold Ringer's solution $\left(1-3^{\circ} \mathrm{C}\right)$. To provide access to MLR cells, the dorsal part of the brain was removed with a vibratome. The giant reticulospinal cell I1 (Rovainen, 1967) was used as a landmark to locate the MLR (Brocard et al., 2010; Ryczko et al., 2013). Retrogradely labeled MLR cells were visualized under a microscope (Nikon Instruments or Olympus) equipped for fluorescence and targeted for whole-cell patch-clamp. Patch pipette $(4-6 \mathrm{M} \Omega$ ) were filled with a solution containing the following (in $\mathrm{mM}$ ): 102.5 cesium methane sulfonate, $1 \mathrm{NaCl}, 1 \mathrm{MgCl}_{2}$, 5 EGTA, 5 HEPES, $0.3 \mathrm{ATP}$, and $0.1 \mathrm{GTP}$. The $\mathrm{pH}$ was adjusted to 7.2 with $\mathrm{CsOH}$, and the osmolarity to $240 \mathrm{mOsm}$ with $\mathrm{H}_{2} \mathrm{O}$. The cellular electrophysiological signals were recorded with a model 2400 amplifier (A-M Systems). To measure the drug effects on the amplitude of synaptic responses, 20 excitatory postsynaptic potentials (EPSPs) were recorded for each cell and for each drug condition.

Glass-coated tungsten microelectrodes (0.7-3.1 M $\Omega$ with $10-40 \mu \mathrm{m}$ exposed tip) and a Grass S88 stimulator (Astro Med) coupled to a Grass PSIU6 photoelectric isolation unit for controlling stimulation intensity (Astro Med) were used for electrical stimulation. The stimulation site was chosen on the basis of previous anatomical and physiological studies (Derjean et al., 2010; Gariépy et al., 2012a; Ryczko et al., 2013) and confirmed by subsequent histology (see Fig. $2 B, C$ ). The electrical stimulation consisted of square pulses ( 2 ms duration) applied with a frequency of $4-5 \mathrm{~Hz}$ for $10 \mathrm{~s}$ to elicit swimming. A pause of 3-5 min was made between two stimulations. Single pulses applied at a frequency of $0.1 \mathrm{~Hz}$ were used to evoke excitatory postsynaptic currents (EPSCs). High-frequency doublet pulses $(20 \mathrm{~Hz})$ were used to test for monosynaptic connectivity. The stimulation intensity ranged from 1 to $32 \mu \mathrm{A}$.

$\mathrm{Ca}^{2+}$ imaging. MLR cells were retrogradely labeled by placing crystal of the $\mathrm{Ca}^{2+}$ indicator $\mathrm{Ca}^{2+}$ green-dextran amines (MW 3000, Invitrogen) at the level of the MRRN, immediately after a complete transverse transection of the brainstem at the level of the MRRN. The preparation was then transferred for $18-24 \mathrm{~h}$ in a chamber perfused with cooled $\left(8-10^{\circ} \mathrm{C}\right)$, oxygenated Ringer's solution to allow the tracer to migrate to fill the MLR cell bodies. The next day, the brain tissue rostral to the PT was removed following a transverse section. As for the patch-clamp recording experiments described above, the dorsal part of the brain was cut away with a vibratome to provide access to MLR cells. The preparation was then pinned down to the bottom of a recording chamber perfused with cooled $\left(8-10^{\circ} \mathrm{C}\right)$, oxygenated Ringer's solution $(4 \mathrm{ml} / \mathrm{min})$. Changes in fluorescence were recorded as previously (Brocard et al., 2010; Ryczko et al., 2016a,b) with a Nikon epifluorescent microscope coupled with a CCD video camera (Photometrics CoolSNAP HQ, Roper Scientific). To measure the changes in fluorescence, regions-of-interest were manually delineated around the MLR cell bodies labeled with the $\mathrm{Ca}^{2+}$ dye. Changes 
in fluorescence of MLR neurons to PT stimulation were acquired at a rate of $2 \mathrm{~Hz}$ using MetaFluor (Universal Imaging). The $\mathrm{Ca}^{2+}$ responses were expressed as the relative changes in fluorescence $(\Delta F / F)$. The baseline was defined as the averaged fluorescence before stimulation. Data analysis was performed using MetaFluor, Clampfit (Molecular Devices) and MATLAB (MathWorks). To measure drug effects on $\mathrm{Ca}^{2+}$ responses, 4-6 responses were recorded for each cell and for each drug condition.

Drug application. Chemicals were purchased from Sigma-Aldrich and diluted to their final concentration in Ringer's solution. In some experiments, bath application of a Ringer's solution containing the AMPA/ Kainate antagonist 6-cyano-7-nitroquinoxaline-2,3-dione (CNQX; $25 \mu \mathrm{M}$ ) and the NMDA antagonist (2R)-amino-5-phosphonovaleric acid (AP5; $100 \mu \mathrm{M})$ was used. In some other experiments, a Ringer's solution containing CNQX (1 mM) and AP5 (0.5 mm; Gariépy et al., 2012a; Ryczko et al., 2016a) or the $\mathrm{D}_{1}$ receptor antagonist SCH 23390 (0.5 mM; Ryczko et al., 2013) was microinjected in the MLR. In some experiments, a Ringer's solution containing D,L-glutamate $(2.5 \mathrm{~mm})$ was also microinjected in the PT. The microinjection procedure was as previously described (Brocard and Dubuc, 2003; Le Ray et al., 2003; Derjean et al., 2010; Gariépy et al., 2012a, 2012b; Ryczko et al., 2013, 2016a,b). The microinjections were done with a glass micropipette (tip diameter of $10-20 \mu \mathrm{m}$ ) using pressure pulses (3-4 psi) of variable duration $(10-80 \mathrm{~ms})$ applied with a Picospritzer (General Valve). Fast green was added to the injected solution to monitor the extent of the injection site. The injected volumes were estimated by measuring the diameter of a droplet ejected in air from the tip of the pipette multiplied by the number of pressure pulses, and the resulting number of moles ejected was calculated for each drug (Le Ray et al., 2003; Ryczko et al., 2013, 2016a,b).

Kinematics. Locomotor movements were monitored with a video camera (Sony HDR-XR200; 30 frames/s) positioned $1 \mathrm{~m}$ above the recording chamber. Data were analyzed offline using homemade software (Brocard et al., 2010; Gariépy et al., 2012a; Ryczko et al., 2013; Juvin et al., 2016). Briefly, tracking markers were equidistantly distributed along the body and monitored over time. Swimming was identified through the presence of mechanical waves traveling from head to tail (Fig. 1; Sirota et al., 2000; Ryczko et al., 2013). To quantify the frequency of swimming movements a single couple of markers located in the middle part of the body was used.

Anatomical tracing and immunofluorescence. These experiments were performed on isolated brain preparations (see above). Biocytin (SigmaAldrich) was used for retrograde labeling of PT cells as previously described (Gariépy et al., 2012a,b, Ryczko et al., 2013, 2016a,b). First, a pulled glass micropipette was used to perform a lesion at the injection site in the MLR and crystals of biocytin were immediately placed in the lesion, allowing the dissolving tracer to be picked up by cut axons. After $10-15 \mathrm{~min}$, the injection site was thoroughly rinsed and the brain was transferred to a chamber perfused with cold oxygenated Ringer's solution overnight to allow retrograde transport of the tracer. The injection site was chosen based on previous studies on the MLR (Derjean et al., 2010; Ryczko et al., 2013; for review see Ryczko and Dubuc, 2013) and verified by histology. The next day, the brain was transferred to a fixative solution according to the immunofluorescence procedure to follow. It is safe to presume that not all axons crossing the injection site were filled by the tracer. Consequently, the labeled cells in the PT constitute an underestimation of the actual number of cells projecting to the MLR in each preparation.

For tyrosine-hydroxylase (TH) immunofluorescence, the whole brain was immersed for $24 \mathrm{~h}$ in $4 \%(\mathrm{w} / \mathrm{v})$ paraformaldehyde in PBS and then transferred to $\mathrm{PB}$ containing $20 \%(\mathrm{w} / \mathrm{v})$ sucrose, both steps at $4^{\circ} \mathrm{C}$. The next day, the brain was sectioned at $25 \mu \mathrm{m}$ thickness with a cryostat. The sections collected on Color-Frost Plus slides (Fisher Scientific) were airdried overnight at $37^{\circ} \mathrm{C}$, after which they were rinsed three times $10 \mathrm{~min}$ in PBS and blocked in PBS containing 5\% normal goat serum and $0.3 \%$ Triton X-100 for $60 \mathrm{~min}$. The sections were then incubated overnight in the blocking solution containing the TH antibody. The next day, they were rinsed three times $10 \mathrm{~min}$ with PBS, incubated in the blocking solution containing the secondary antibody for $60 \mathrm{~min}$, and rinsed again three times $10 \mathrm{~min}$ in PBS. The slides were immediately coverslipped using Vectashield (with or without DAPI, H-1200, H-1000; Vector Laboratories) as mounting medium.
The presence of dopamine (DA) and glutamate was detected by immunofluorescence concurrently or separately. The brain was immersed for $17-18 \mathrm{~h}$ in a $0.05 \mathrm{M}$ Tris buffered $0.1 \%$ sodium metabisulfite and $0.8 \%$ $\mathrm{NaCl}$ (TBSM; pH 7.4) solution containing $2 \%$ glutaraldehyde. The brain was then transferred to TBSM containing $20 \%$ (w/v) sucrose overnight. The last two steps were performed at $4{ }^{\circ} \mathrm{C}$. The next day, the brain was cut on a cryostat. Sections of $25 \mu \mathrm{m}$ thickness were collected on slides and air-dried overnight. The sections were then rinsed three times $10 \mathrm{~min}$ and incubated in TBSM containing 1\% sodium borohydride for $30 \mathrm{~min}$. After three rinses in TBSM, the sections were incubated in TBSM containing $5 \%$ normal goat serum and $0.3 \%$ Triton X-100 for $60 \mathrm{~min}$. The sections were then incubated overnight at $4^{\circ} \mathrm{C}$ in the blocking solution containing the DA and/or the glutamate primary antibodies. The next day, the sections were rinsed three times $10 \mathrm{~min}$ with TBSM, incubated in the blocking solution containing the appropriate secondary antibodies (see below) for $60 \mathrm{~min}$, and rinsed again three times $10 \mathrm{~min}$ in TBSM. The slides were then immediately coverslipped as described for TH.

For TH immunofluorescence, a rabbit anti-TH primary antibody was used (diluted 1:400; AB152; Millipore) followed by a donkey anti-rabbit AlexaFluor 594 (diluted 1:400; A21207; Invitrogen) or a goat anti-rabbit AlexaFluor 488 (1:400; A11008; Invitrogen). TH immunofluorescence was sometimes used in the present study as an alternative to DA immunofluorescence to visualize the DA neurons in the PT, based on studies in lampreys (Pombal et al., 1997; Abalo et al., 2005; Pierre et al., 1997; Ryczko et al., 2013). The AB152 antibody against TH has been used reliably on lampreys in many independent studies by different research groups on DA neurons (Villar-Cerviño et al., 2006; Barreiro-Iglesias et al., 2008; Robertson et al., 2012; Ryczko et al., 2013). For DA immunofluorescence, a mouse anti-DA primary antibody was used (diluted 1:400; MAB5300; Millipore) followed by a either a goat anti-mouse AlexaFluor 488 (diluted 1:400; A11001; Invitrogen) or a goat anti-mouse DyLight 594 (diluted 1:400; 115-515-146; Jackson ImmunoResearch). The specificity of the MAB5300 antibody for DA was tested by ELISA by the manufacturer, and its pattern of labeling in our material corresponded closely to that reported with other DA antibodies in the lamprey (Abalo et al., 2005; Pierre et al., 1997). We have also independently confirmed that the THimmunoreactive neurons in the PT use DA as neurotransmitter (Ryczko et al., 2013). For glutamate immunofluorescence, a rabbit polyclonal primary antibody directed against glutamate was used (diluted 1:5000; IG1007, lot 3603, ImmunoSolution) followed by either a goat anti-rabbit AlexaFluor 594 antibody (diluted 1:400; A11012, Invitrogen) or a goat anti-rabbit AlexaFluor 488 (diluted 1:400; A11008, Invitrogen). The IG1007 glutamate antibody has been used successfully to label glutamatergic neurons in the lamprey brain (Barreiro-Iglesias et al., 2008; VillarCerviño et al., 2011; Fernández-López et al., 2012) and in salamanders (Ryczko et al., 2016a). The specificity of the antibody was confirmed by dot blots performed by the supplier, which revealed no immunoreaction against a variety of amino acid conjugates such as aspartate. Western blots did not yield staining of lamprey brain proteins extracts (Barreiro-Iglesias et al., 2008; Villar-Cerviño et al., 2011). The staining is similar to that obtained with a mouse monoclonal antibody directed against glutamate (FernándezLópez et al., 2012). Brain regions stained by the antibody used in the present study also contained neurons expressing the vesicular transporter for glutamate mRNA (Villar-Cerviño et al., 2011).

In double DA/glutamate immunofluorescence experiments, the primary antibodies, and the secondary antibodies, were mixed together. The specific labeling obtained under these conditions was in every ways similar to the labeling obtained when the antibodies were each used separately. Biocytin was visualized with streptavidin Alexa Fluor594, 488, or 350 (diluted 1:400; Life Technologies), which was added to the secondary antibodies' solution without altering the immunofluorescence labeling.

In all cases, omitting the primary antibody from the procedures resulted in the absence of specific labeling on the brain sections.

The sections were then observed and photographed using an E600 epifluorescence microscope equipped with a DXM1200 digital camera (Nikon). For some sections, a confocal microscope was used (FV1000, Olympus). Photoshop CS5 (Adobe) was used to combine digital photomicrographs taken with different filter sets and to adjust the levels so that all fluorophores were clearly visible simultaneously. 


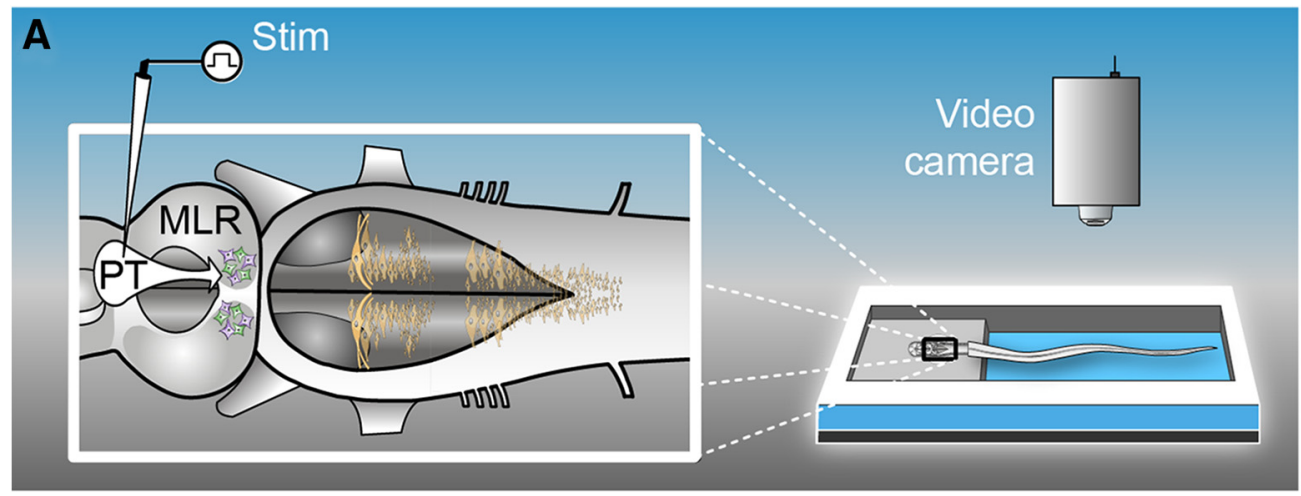

B
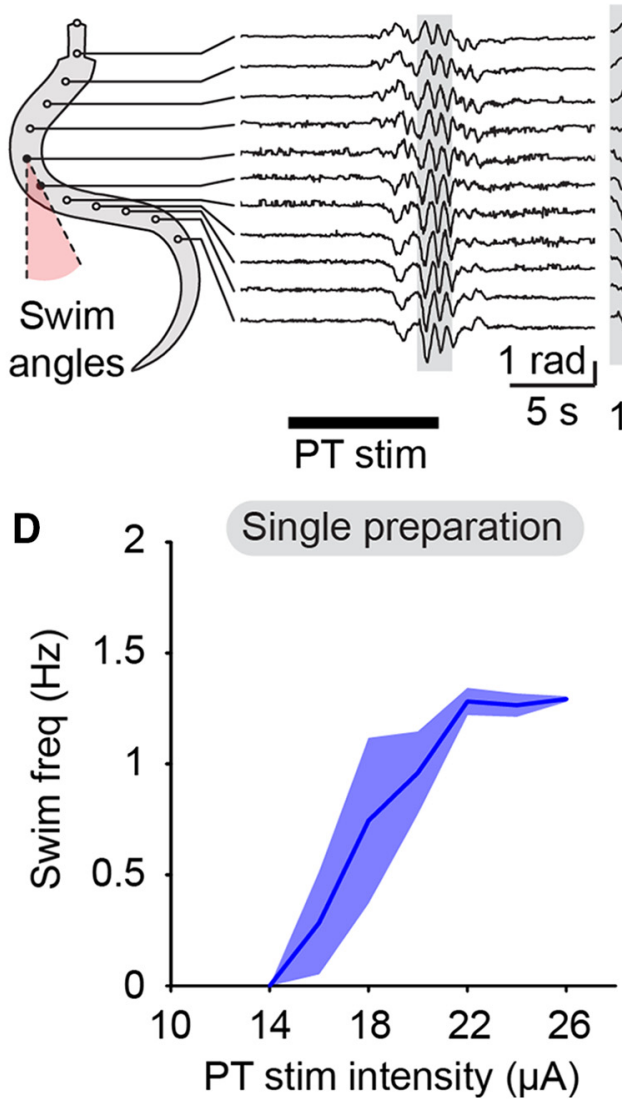

C $\quad 85 \%$ of $\max$

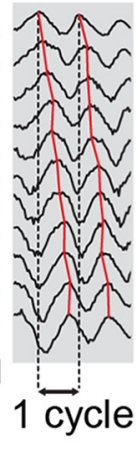

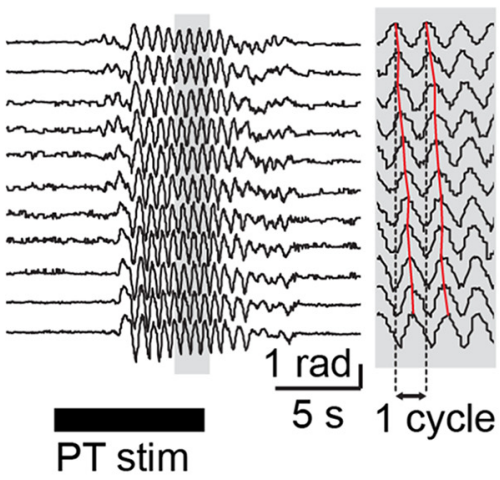

E

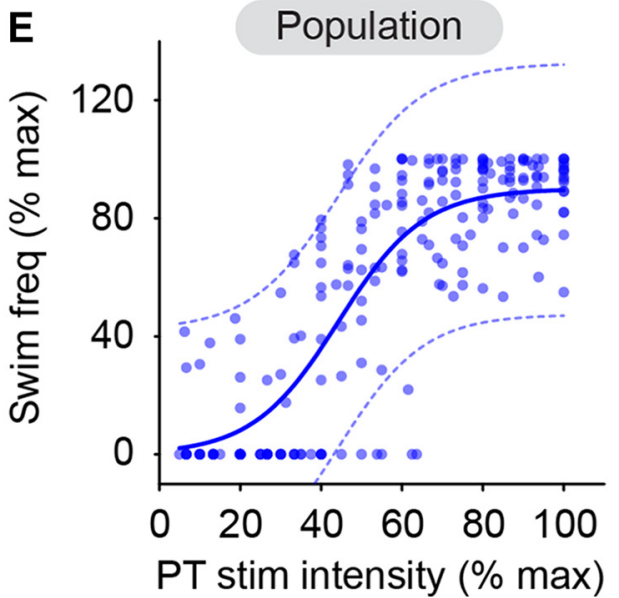

Figure 1. Incremental stimulation of the PT evokes gradual increase in swimming frequency. $A$, In a semi-intact preparation, the PT was stimulated electrically and locomotion was quantified by placing equidistant markers along the body (see Materials and Methods). Angular variations (radians) of the body curvature were measured over time. B, C, PT stimulation elicited swimming as illustrated by head-to-tail mechanical waves ( $\boldsymbol{B}$ and $\boldsymbol{C}$, gray insets, where red solid lines indicate the maximal bending curvature for each marker). Increasing PT stimulation intensity (18-22 $\mu \mathrm{A}$, i.e., $69-85 \%$ of the maximal stimulation intensity used in this preparation) increased swimming frequency. $\boldsymbol{D}$, Plot illustrating swimming frequency (mean \pm SEM; $2-3$ trials per stimulation intensity) as a function of PT stimulation intensity for the preparation shown in $B$ and $C$. $E$, Relationship between swimming frequency (blue dots; $n=213$ trials pooled from 17 preparations) and PT stimulation intensity (1-32 $\mathrm{AA}, 10 \mathrm{~s}$ train, $2 \mathrm{~ms}$ pulses, $4-5 \mathrm{~Hz}$ ). Data followed a sigmoidal function (blue solid line; $R^{2}=0.69, p<0.0001$ ). The dotted lines illustrate the $95 \%$ prediction intervals. Locomotor frequency and stimulation intensity were expressed as a percentage of their maximal values.

Statistics. Data in the text are presented as the mean \pm SEM. For $\mathrm{Ca}^{2+}$ imaging, measurements of the area under the curve from the beginning of the response to the return to baseline were calculated using a calculation script in Clampfit (Molecular Devices). The values were expressed in $\Delta F / F \times s$. Correlations between variables and their significance as well as $95 \%$ confidence intervals were calculated using Sigma-Aldrich Plot 11.0. No statistical method was used to predetermine sample sizes. The sample sizes in the present study are in general similar to those used in the field. No randomization or blinding procedure was used. Parametric analyses were used when assumptions for normality and equal variance were respected, other- wise nonparametric analyses were used. Two-tailed paired Student's $t$ tests were performed for comparing means between two dependent groups. For more than two dependent groups, a parametric one-way ANOVA for repeated measures or a nonparametric Friedman ANOVA on ranks for repeated measures was used. When two factors were tested, a two-way ANOVA for repeated measures on ranks was performed. Both ANOVA analyses were followed by a Student-Newman-Keuls post hoc test for multiple comparisons between groups. Statistical differences were assumed to be significant when $p<0.05$.

Data availability. All relevant data are available from the authors. 
A

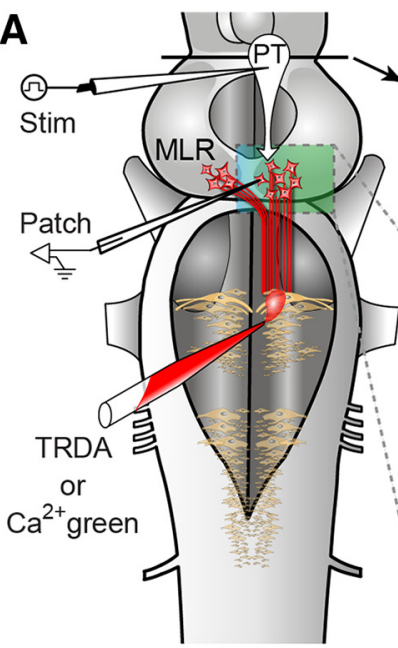

$\mathbf{E}$
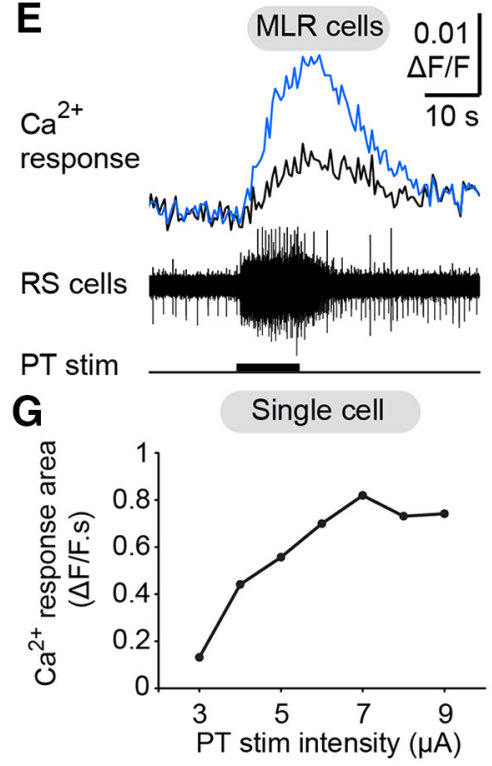

I
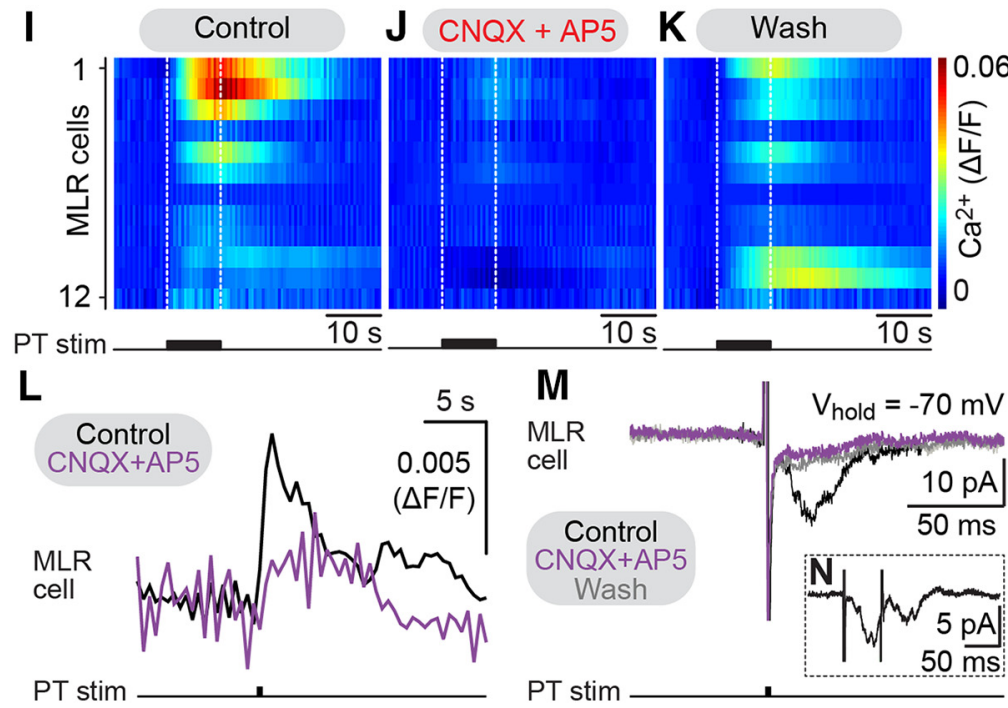

Figure 2. Incremental stimulation of the PT gradually increases MLR cell responses. $\boldsymbol{A}$, Retrogradely labeled MLR cells were recorded using calcium $\left(\mathrm{Ca}^{2+}\right)$ imaging or patch-clamp electrodes in an isolated brainstem preparation. $\boldsymbol{B}, \boldsymbol{C}$, The stimulation site in the PT (enclosed by a red dashed line) was located within TH-immunoreactive cells (black). D, Two MLR cells (blue and black circles) labeled with $\mathrm{Ca}^{2+}$ green dextran amines. The giant reticulospinal (RS) cell I1, a MLR landmark, is enclosed by a white dashed circle. $\boldsymbol{E}$, Chemical stimulation of the PT with glutamate $\left(2.5 \mathrm{~mm}, 2 \mathrm{~Hz}, 50\right.$ ms pulses, 24 pulses) elicited $\mathrm{Ca}^{2+}$ rise in MLR cells together with activation of $R S$ cells recorded extracellularly. $F, C^{2+}$ increases $(\Delta F / F)$ in a $M L R$ cell in response to incremental electrical PT stimulations ( $10 \mathrm{~s}$ train, $5 \mathrm{~Hz}, 2 \mathrm{~ms}$ pulses). $\mathbf{G}$, Plot of $\mathrm{Ca}^{2+}$ response versus PT stimulation intensity in the MLR cell in $\boldsymbol{F}$.

\section{Results}

We first confirmed that electrical stimulation of the PT robustly evokes swimming (Fig. $1 A, B$ ) in a lamprey semi-intact preparation in which the brain is exposed for stimulation, while the body swims in the chamber (Derjean et al., 2010; Gariépy et al., 2012a; Ryczko et al., 2013). We then examined whether PT stimulation could evoke graded locomotor output. A progressive increase in the PT stimulation intensity (1-32 $\mu \mathrm{A}, 4-5 \mathrm{~Hz}, 2 \mathrm{~ms}$ pulses, $10 \mathrm{~s}$ trains) elicited a graded increase in swimming frequency (Fig. $1 B-D ; n=17$ preparations). The recorded swimming frequencies $(0.3-3.6 \mathrm{~Hz})$ are in the range observed in freely moving lampreys (Islam and Zelenin, 2008). Data were pooled by expressing the locomotor frequency as a percentage of the maximal locomotor frequency. The PT stimulation intensity was expressed as a percentage of maximal stimulation intensity, that was defined when the locomotor response reached a plateau and did not grow further as the stimulation intensity was increased, as previously done in lampreys (Brocard et al., 2010) and salamanders (Ryczko et al., 2016a). The relationship between PT stimulation intensity and locomotor frequency followed a sigmoidal function, with swimming frequencies reaching a plateau at higher stimulation intensities (Fig. $1 E ; R^{2}=0.69, p<0.0001, n=213$ trials pooled 17 preparations). These findings establish that incremental PT stimulation evokes graded intensification of swimming frequency.

\footnotetext{
$\boldsymbol{H}$, Relationship between MLR cell $\mathrm{Ca}^{2+}$ response area $(n=$ 56 trials, 10 cells from 4 preparations) and PT stimulation intensity (2-10 $\mu \mathrm{A}, 10$ s train, $5 \mathrm{~Hz}, 2 \mathrm{~ms}$ pulses) both expressed as a percentage of their maximal values. $\boldsymbol{I}-\boldsymbol{K}$, Color plots illustrating MLR $\mathrm{Ca}^{2+}$ responses $(\Delta F / F)$ in response to PT stimulation (5-10 $\mu \mathrm{A}, 10 \mathrm{~s}$ train, $5 \mathrm{~Hz}, 2$ ms pulses) in control condition, following 7-22 min bath application of CNQX (25 $\mu \mathrm{M})$ and AP5 (100 $\mu \mathrm{M})$, and 60-77 min after wash out. Each line illustrates the response of individual MLR cells ( $n=$ 12 cells from 4 preparations). White dotted lines indicate onset and offset of PT stimulation. Warmer colors (red) indicate larger $\mathrm{Ca}^{2+}$ responses. $L, \mathrm{Ca}^{2+}$ responses $(\Delta F / F)$ elicited by single-pulse stimulation of the PT $(0.1 \mathrm{~Hz}, 15 \mu \mathrm{A}, 2 \mathrm{~ms}$ pulses $)$ in MLR neurons were abolished by bath application of CNQX $(25 \mu \mathrm{M})$ and AP5 $(100 \mu \mathrm{M})$. Each trace is the average of the pooled $\mathrm{Ca}^{2+}$ responses obtained in three MLR neurons. In each neuron, five trials were recorded for each condition. $M$, EPSCs evoked by PT stimulation $(0.1 \mathrm{~Hz}, 5-9 \mu \mathrm{A}, 2 \mathrm{~ms}$ pulses) in voltage-clamped MLR neurons were reduced by bath-applied CNQX (25 $\mu \mathrm{M})$ and AP5 (100 $\mu \mathrm{M})$. Each trace is the average of 10 EPSCs. Only a partial washout was obtained for this cell. $\boldsymbol{N}$, EPSCS (average of 60 trials) induced in a MLR neuron by high-frequency doublets $(20 \mathrm{~Hz})$ applied to the PT. TRDA, Texas Red dextran amines.
} 
A

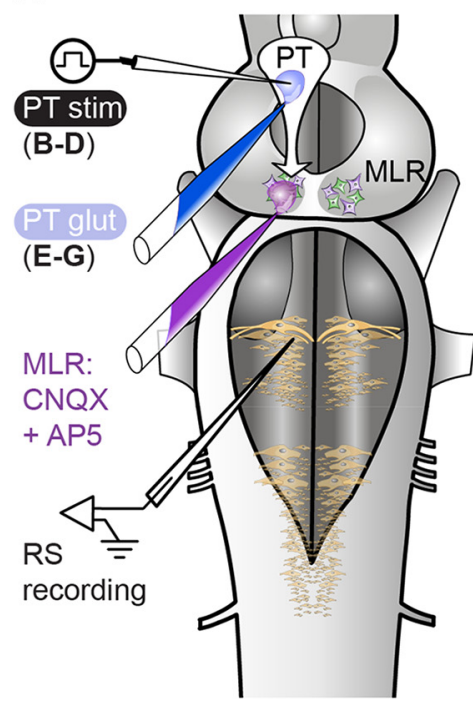

B

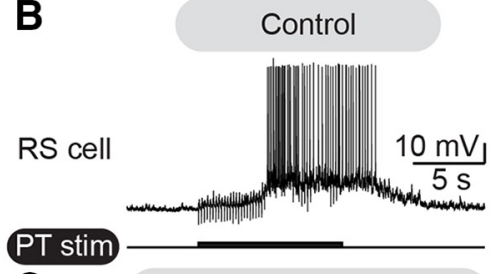

MLR: CNQX+AP5
E

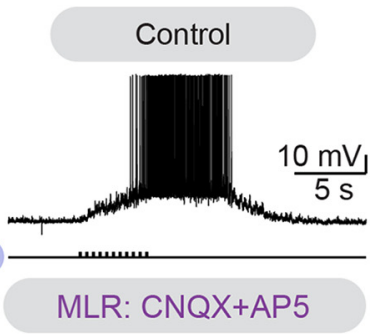

RS cell

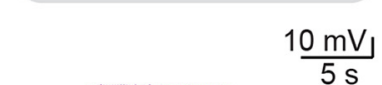

PT stim
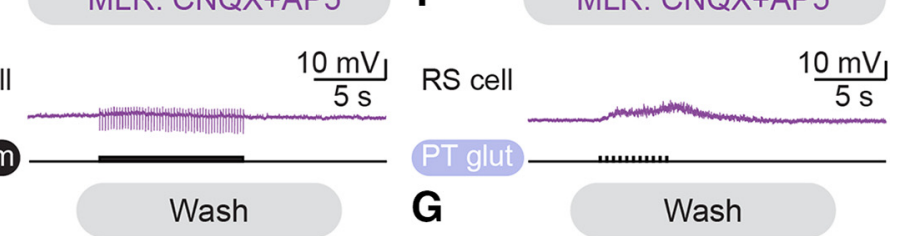

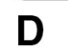

Wash

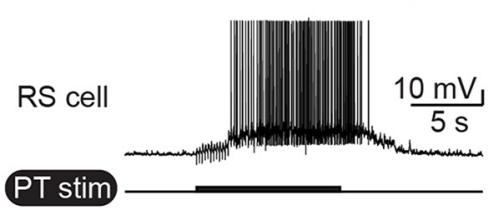

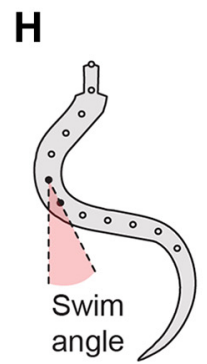

\title{
I
}

\begin{abstract}
Swim angle
\end{abstract}

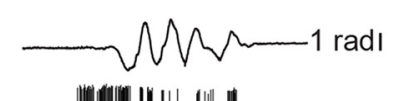

Control

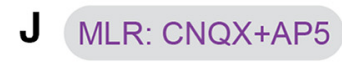

K
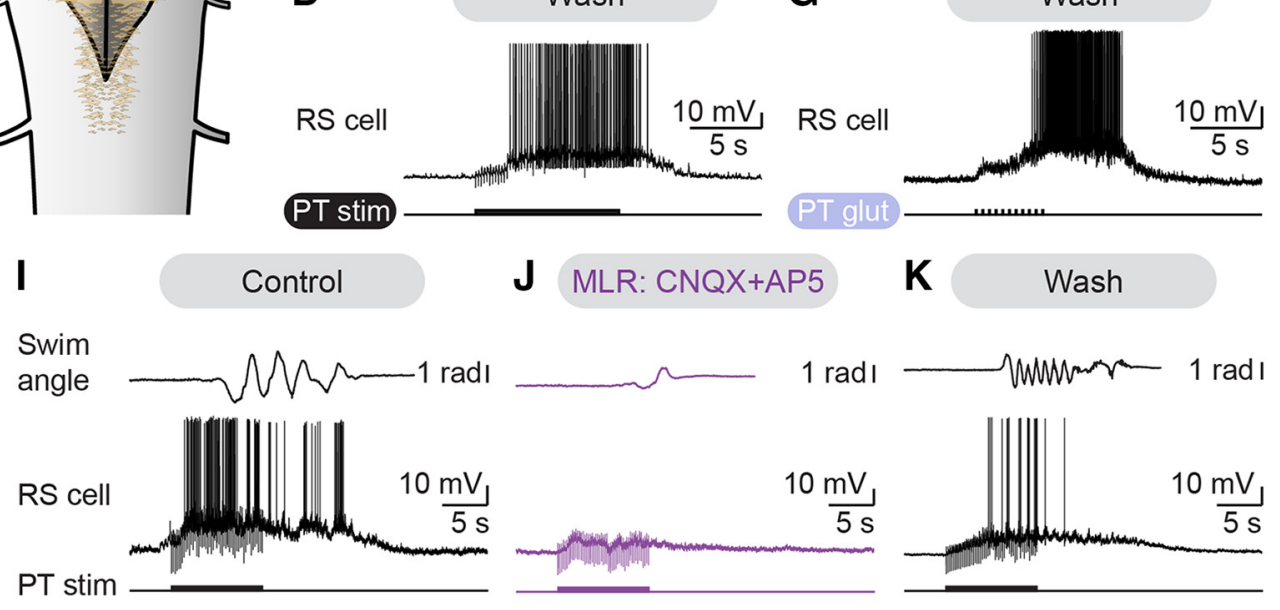

Figure 3. The descending glutamatergic drive from the PT to the MLR evokes reticulospinal activity and locomotion. $A$, In isolated brainstem preparations, glutamatergic antagonists were microinjected in the MLR. RS activity was recorded extracellularly in response to electrical ( $2 \mathrm{~ms}$ pulses, $5 \mathrm{~Hz}, 10 \mathrm{~s}$ train, $8-12 \mu \mathrm{A}$ ) or chemical stimulation (glutamate $2.5 \mathrm{~mm}, 20-80 \mathrm{~ms}$ pulses, 2 $\mathrm{Hz}, 9-11$ pulses) of the PT. B-D, Microinjection of 36.4-78.4 pmol of CNQX (1 mM) and 18.2-39.2 pmol of AP5 in the MLR (0.5 mM) dramatically decreased RS activity elicited by PT stimulation (7 $\mu \mathrm{A}, 10 \mathrm{~s}$ train, $2 \mathrm{~ms}$ pulses, $4 \mathrm{~Hz}$ ). Recovery was obtained after $62-108 \mathrm{~min}$ of washout. $\boldsymbol{E}-\boldsymbol{G}$, Microinjection of 51.5-119.9 pmol of CNQX (1 mM) and $25.7-156.4 \mathrm{pmol}$ of AP5 (0.5 mM) in the MLR reduced RS activity elicited by PT chemical stimulation with $1.0-19.1$ pmol of glutamate (illustrated case: 50 ms pulses, $2 \mathrm{~Hz}, 11$ pulses). Responses recovered after $88-135$ min of wash out. $\boldsymbol{H}$, In a semi-intact preparation where RS neurons were recorded intracellularly to monitor the activity of brainstem locomotor circuits, glutamatergic antagonists were microinjected in the MLR. Angular variations (radians) of the curvature of a mid-body segment were measured over time during swimming. $\boldsymbol{I}-\boldsymbol{K}$, Microinjections of $34.8-68.4 \mathrm{pmol}$ of CNQX (1 mM) and $17.4-34.2 \mathrm{pmol}$ of AP5 (0.5 $\mathrm{mm}$ ) in the MLR dramatically reduced RS activity and swimming movements elicited by PT stimulation (illustrated case: $10 \mu \mathrm{A}, 10 \mathrm{~s}$ train, $2 \mathrm{~ms}$ pulses, $5 \mathrm{~Hz}$ ). These effects were reversed after $48-135$ min of washout. Data from $\boldsymbol{B}-\boldsymbol{D}, \boldsymbol{E}-\boldsymbol{G}$, and $\boldsymbol{I}-\boldsymbol{K}$ are from three different preparations.

Then, we examined whether MLR cells are directly controlled in a graded fashion by descending inputs from the PT. We performed $\mathrm{Ca}^{2+}$ imaging of MLR cells in isolated brain preparations. MLR cells were retrogradely labeled with a $\mathrm{Ca}^{2+}$ indicator injected in the dendritic field of reticulospinal neurons. The dorsal part of the brain (i.e., the tectum) was removed to provide access to MLR cells for $\mathrm{Ca}^{2+}$ imaging (Fig. 2A). Reticulospinal cells were recorded extracellularly to monitor the activity of brainstem locomotor networks downstream the MLR. Stimulation of the PT (Fig. $2 B, C$ ) elicited $\mathrm{Ca}^{2+}$ responses in MLR cells together with reticulospinal activity (Fig. $2 D, E$ ). Increasing the intensity of the PT stimulation increased the size of the $\mathrm{Ca}^{2+}$ response in MLR cells (Fig. $2 F, G$ ). The relationship between normalized $\mathrm{Ca}^{2+}$ responses in the MLR and PT stimulation intensity also followed a sigmoidal function (Fig. $2 H ; R^{2}=0.71, p<$ $0.0001, n=56$ trials, 10 cells pooled from 4 preparations). These results indicate that incremental increase in PT stimulation evokes graded intensification of MLR cell activation.

We then examined whether glutamatergic transmission was involved. Bath application of glutamatergic antagonists (CNQX $25 \mu \mathrm{M}$, AP5 $100 \mu \mathrm{M})$ dramatically decreased the area of the $\mathrm{Ca}^{2+}$ responses evoked in MLR cells by trains of PT stimulation (reduced by $86.5 \pm 5.1 \%, p<0.05$ vs control, Student-Newman-
Keuls test, $n=12$ cells pooled from 4 preparations; Fig. $2 I, J)$. The responses returned to $76.4 \pm 16.1 \%$ of control after wash out $(p<0.05$ vs CNQX/AP5, Student-Newman-Keuls test; Fig. $2 K$ ). Similarly, bath applied glutamatergic antagonists also significantly decreased the responses evoked by single-pulse stimulation in MLR cells recorded either with $\mathrm{Ca}^{2+}$ imaging (reduced by $90.7 \pm 23.1 \%, p<0.01$ vs control, paired $t$ test, $n=3$ cells; Fig. $2 L$ ) or patch-clamp recordings (reduced by $64.7 \pm 1.6 \%$ in cell 1 , $p<0.05$ vs control, Student-Newman-Keuls test; reduced by $38.3 \pm 4.1 \%$ in cell $2, p<0.001$ vs control, Student-NewmanKeuls test; Fig. 2M). The PT to MLR connection is likely monosynaptic as MLR cell responses followed high-frequency $(20 \mathrm{~Hz})$ stimulation doublets applied to the PT ( $n=5$ cells of 5 tested, data pooled from 3 preparations; Fig. $2 N$ ). Altogether, this shows that glutamatergic transmission is involved in the PT-evoked responses in MLR cells.

Next, we investigated whether the descending glutamatergic drive from the PT to the MLR was responsible for the activation of the locomotor circuits downstream the MLR. Electrical stimulation of the PT elicited reticulospinal discharges in isolated brain preparations. Microinjection in the MLR of the glutamatergic antagonists CNQX ( $1 \mathrm{~mm}$ ) and AP5 (0.5 mM) dramatically decreased the discharge frequency elicited in reticulospinal neu- 
A
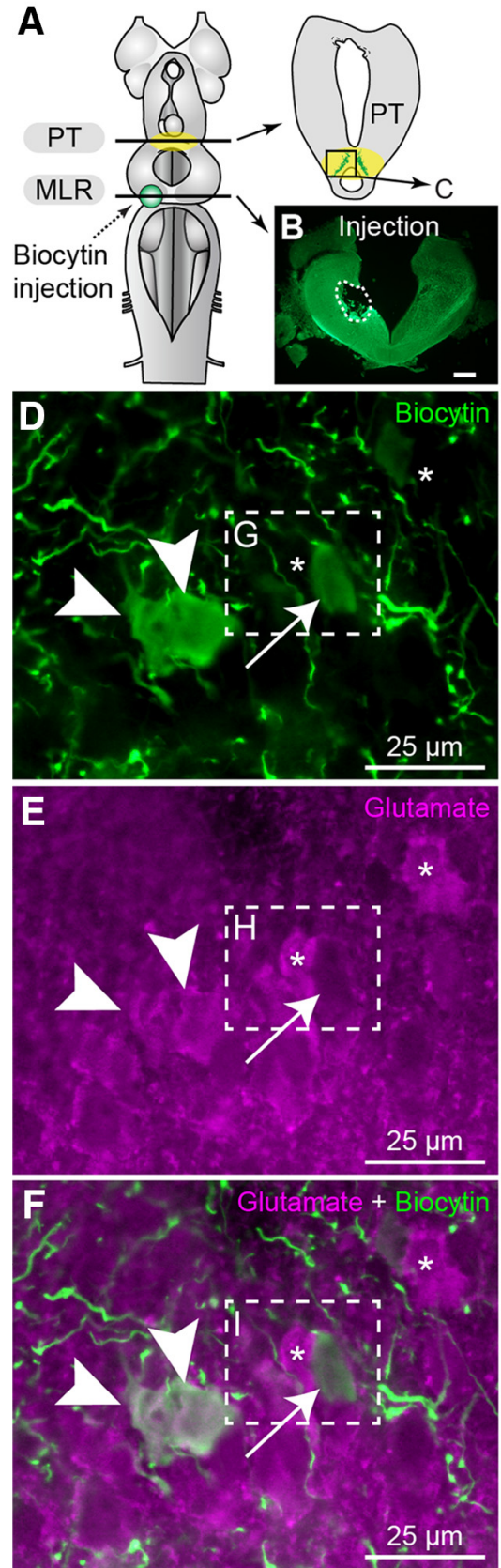
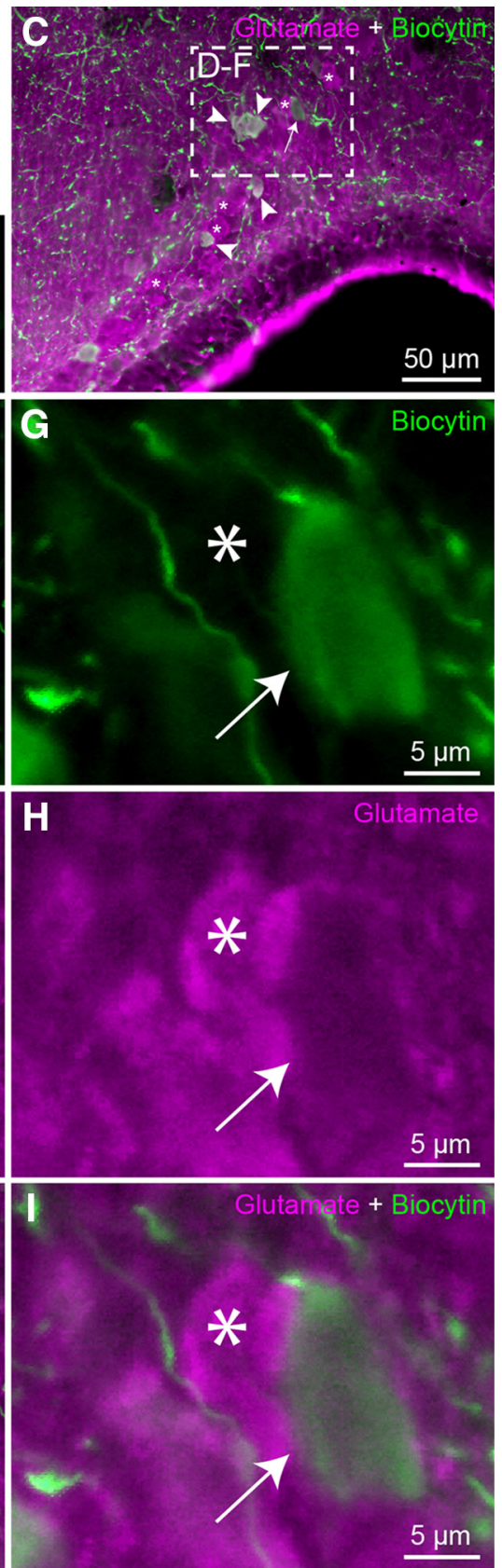

Figure 4. Glutamatergic neurons of the PT send descending projections to the MLR.A, Schematic dorsal view of a lamprey brain. The diagram on the right illustrates a cross section at the level of the PT (homologous to the mammalian substantia nigra pars compacta) with the approximate location of the micrographs shown in $\mathbf{C}-\boldsymbol{F}$. $\boldsymbol{B}$, The photomicrograph illustrates the tracer (biocytin, green) injection site (enclosed by a white dashed line) in the MLR. Scale bar, $300 \mu \mathrm{m}$. C, Cells labeled in the PT following biocytin (green) injection in the MLR and immunofluorescence against glutamate (magenta). $\boldsymbol{D}-\boldsymbol{F}$, Magnification of the dashed rectangle in C. G-I, Magnifications of the dashed rectangles in $\boldsymbol{D}-\boldsymbol{F}$. $\mathbf{C}-\boldsymbol{I}$, White arrowheads indicate retrogradely labeled cells that were immunopositive for glutamate in the PT. Asterisks denote cells positive for glutamate but not retrogradely labeled. The white arrow points to a cell retrogradely labeled but not immunopositive for glutamate.

rons by electrical PT stimulation (reduced by $92.3 \pm 4.9 \%, p<$ 0.001 vs control, Student-Newman-Keuls test, $n=15$ trials pooled from 3 preparations; Fig. $3 A-C$ ). After wash out, the responses recovered with spiking frequency returning to $86.7 \pm$ $12.8 \%$ of control ( $p<0.001$ vs CNQX/AP5, Student-NewmanKeuls test; Fig. $3 D$ ). Because electrical stimulation can recruit fibers of passage in addition to local cell bodies, electrical stimulation was replaced with chemical stimulation (Fig. 3A,E-G). Such chemical stimulation likely activates local cell bodies that are dopaminergic, glutamatergic and possibly from other types. Microinjections of glutamate $(2.5 \mathrm{~mm})$ onto the PT elicited discharges in reticulospinal cells similar to those evoked by electrical stimulation. Local microinjections of CNQX (1 mM) and AP5 (0.5 mM) in the MLR decreased the discharge frequency of reticulospinal neurons (reduced by $84.0 \pm 4.2 \%, p<0.05$ vs control, Student-Newman-Keuls test, $n=20$ trials pooled from 4 preparations). Recovery was obtained after wash out of the glutamatergic antagonists, with spiking frequency increasing back to $97.8 \pm$ $15.4 \%$ of control ( $p<0.05$ vs CNQX/ AP5, Student-Newman-Keuls test). In semi-intact preparations (Fig. $3 \mathrm{H}$ ), microinjections of CNQX (1 mM) and AP5 $(0.5 \mathrm{mM})$ in the MLR dramatically decreased the frequency of locomotor movements evoked by PT stimulation (reduced by $61.3 \pm 10.3 \%, p<0.001$ vs control, Student-Newman-Keuls test; Fig. 3I,J). Recovery was obtained after wash out with the locomotor frequency returning to $96.4 \pm 6.4 \%$ of control $(p<0.001$ vs CNQX/AP5, Student-Newman-Keuls test, $n=18$ trials per condition pooled from 3 preparations; Fig. $3 K$ ). Similar results were obtained in semi-intact preparations for the discharge frequency of reticulospinal neurons following microinjections of glutamatergic antagonists in the MLR (reduced by $93.0 \pm 3.0 \%, p<0.001$ vs control, Student-Newman-Keuls test). These effects were also reversed after washout with frequency returning to $71.5 \pm$ $7.6 \%$ of control $(p<0.001$ vs CNQX/ AP5, Student-Newman-Keuls test). Altogether, these results show that the descending glutamatergic pathway from the PT to the MLR plays an important role in the activation of locomotor circuits downstream the MLR.

We then looked for the anatomical substrate of these effects. We examined whether glutamatergic PT neurons send a descending projection to the MLR with anatomical techniques. Glutamatergic neurons were found in the PT ( $n=9$ preparations). We injected an axonal tracer in the MLR to label retrogradely neurons in the PT (Fig. $4 A, B$ ) and we observed that several of those were immunoreactive for glutamate (Fig. $4 C-I ; n=7$ preparations). Because a descending dopaminergic pathway originating from the PT to the MLR was previously reported (Ryczko et al., 2013; Pérez-Fernández et al., 2014), we examined whether PT glutamatergic cells were a separate population from the PT dopaminergic ones. Using double-labeling experiments, we found that several PT neurons were colabeled for dopamine and glutamate (Fig. $5 A-I ; n=6$ preparations). To determine whether PT neurons co-storing dopamine and glutamate sent descending projections to the MLR, we added a retro- 
grade tracer injection in the MLR (Fig. $6 A, B)$ in a series of triple labeling experiments. We found that several PT cells projecting down to the MLR were colabeled for dopamine and glutamate $(n=4$ preparations; Fig. $6 C-K$ ). PT neurons storing only dopamine or glutamate were also found to send descending projections to the MLR. Altogether, these results provide direct evidence of a glutamatergic pathway from the PT to the MLR, in parallel with the previously characterized dopaminergic pathway (Ryczko et al., 2013; Pérez-Fernández et al., 2014). There is thus an anatomical substrate for interaction between these two transmitters at the level of the MLR.

Next, we examined the role of the interactions between glutamatergic and dopaminergic inputs from the PT to the MLR in the graded control of locomotor movements. We previously showed that PT-evoked dopamine release in the MLR increases swimming frequency through the activation of $D_{1}$ receptors (Ryczko et al., 2013). Here we examined in semiintact preparations whether the activation of $D_{1}$ receptors in the MLR is needed to evoke graded swimming when stimulating the PT with increasing intensities. When the $\mathrm{D}_{1}$ antagonist SCH 23390 (0.5 mM) was microinjected in the MLR, the locomotor frequency of PT-evoked swimming was decreased as expected, but graded control of swimming was still possible when stimulating the PT with increasing intensities (Fig. 7A). Similar observations were made when pooling the data by expressing stimulation intensity and locomotor frequency as a function of their maximal values (Fig. $7 B-D$ ). In control conditions, the relationship between stimulation intensity and swimming frequency followed a sigmoid function $\left(R^{2}=\right.$ $0.78, p<0.0001, n=81$ trials pooled from 6 preparations) that persisted in the presence of the $D_{1}$ antagonist injected in the $\operatorname{MLR}\left(R^{2}=0.76, p<0.0001, n=81\right.$ trials pooled from 6 preparations), indicating that progressive increase in stimulation intensity still elicited graded increase in swimming. After wash out of the drug, the sigmoid relation was still present $\left(R^{2}=\right.$ 0.83, $p<0.0001, n=81$ trials pooled from 6 preparations). Statistical analysis confirmed that the $\mathrm{D}_{1}$ antagonist reversibly decreased locomotor frequency especially at maximal PT stimulation intensities (Fig. 7E). This might be explained by a "floor effect" at lower intensities, where the range of evoked swimming frequencies could be too narrow to detect significant differences between drug conditions. In the presence of the $\mathrm{D}_{1}$ antagonist, the locomotor frequencies reached a plateau that was lower than under control conditions at 50,60,70,80, 90, and 100\% of maximal stimulation intensities $(p<0.05$ to $p<0.001$ against con-
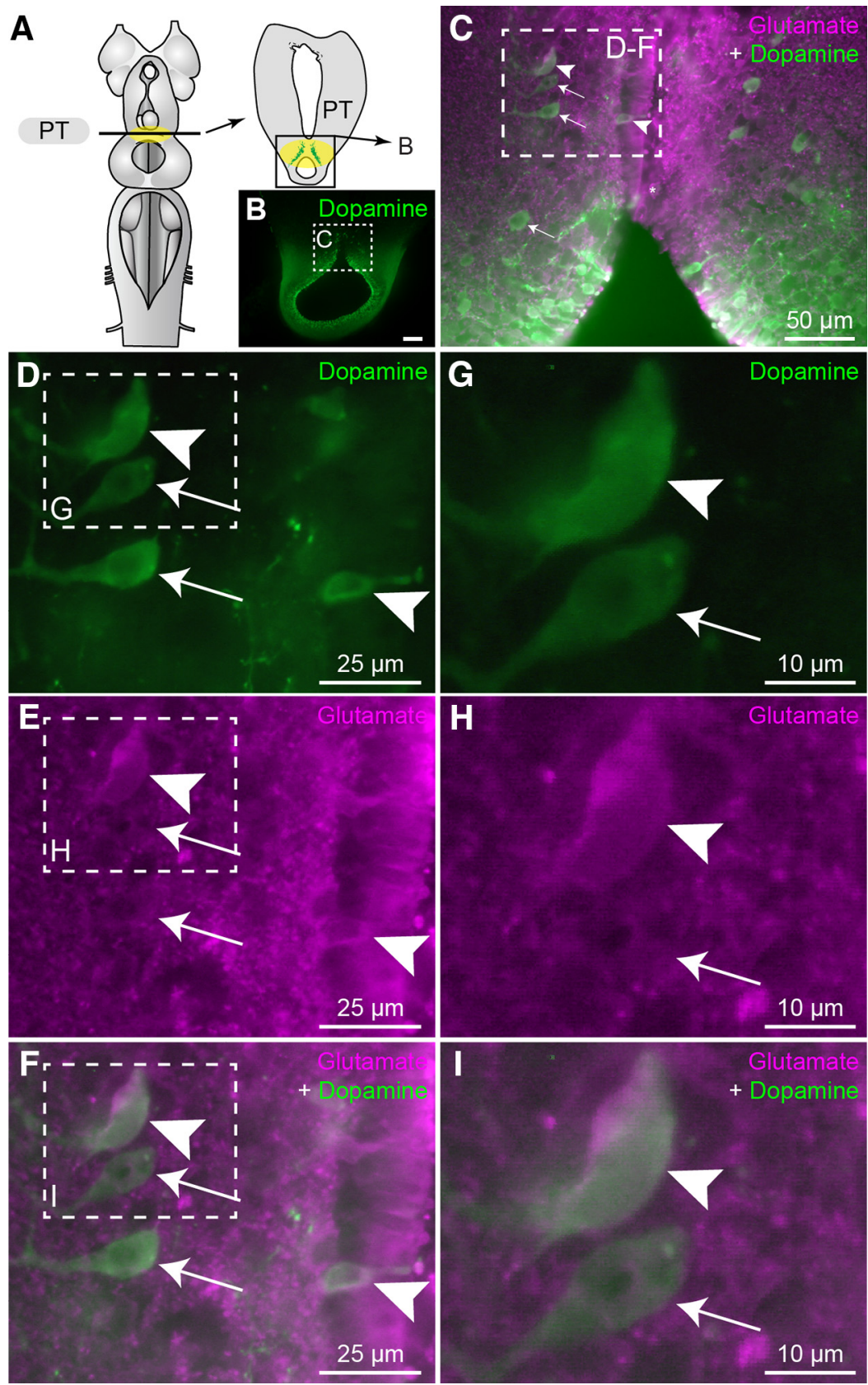

Figure 5. Colabeling of dopamine and glutamate in neurons of the PT.A, Schematic dorsal view of a lamprey brain. The diagram on the right illustrates a cross section at the level of the PT (homologous to the mammalian substantia nigra pars compacta) with the approximate location of the micrograph in $\boldsymbol{B}$. $\boldsymbol{B}$, Transverse section of the PT showing dopaminergic neurons (green), and the location of the micrograph shown in $\boldsymbol{C}$. $\boldsymbol{C}$, Magnification of the dashed rectangle in $\boldsymbol{B}$, merged with immunofluorescence against glutamate (magenta). $\boldsymbol{D}-\boldsymbol{F}$, Magnification of the dashed rectangle in $\mathbf{C}$. $\mathbf{G}-\boldsymbol{I}$, Magnifications of the dashed rectangles in $\boldsymbol{D}-\boldsymbol{F}$. $\boldsymbol{C}-\boldsymbol{I}$, White arrowheads illustrate cells showing immunofluorescence against glutamate (magenta) and dopamine (green). White arrows point to cells immunopositive for dopamine but not for glutamate.

trol, Student-Newman-Keuls test after a two-way ANOVA on ranks for repeated measures, $p<0.001$; Fig. $7 E$ ). This effect was abolished after wash out at 50,60,70, 90, and 100\% of maximal stimulation intensities ( $p<0.05$ to $p<0.001$ against drug injection, Student-Newman-Keuls test). Because we previously demonstrated that a small number of dopamine cells in the PT send descending projections to the contralateral MLR (Ryczko et al., 2013), microinjections of the $D_{1}$ antagonist were performed on both sides of the MLR ( $n=5$ preparations). The effects were very similar to those observed with a unilateral injection of the drug. 

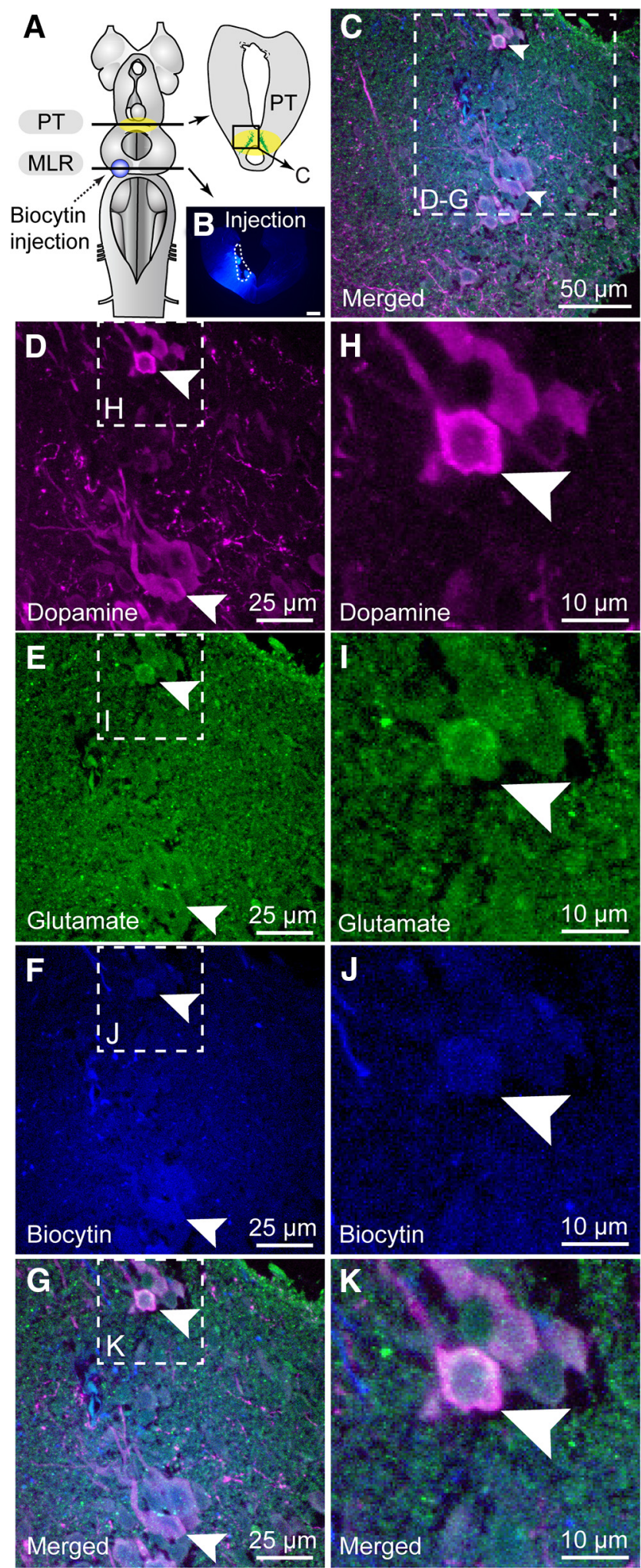

Figure 6. Neurons colabeled for dopamine and glutamate in the PT send descending projections to the MLR. A, Schematic dorsal view of a lamprey brain. The diagram in the top right corner illustrates a cross section at the level of the PT (homologous to the mammalian substantia nigra pars compacta) with the approximate location of the micrograph shown in $\boldsymbol{C}$. $\boldsymbol{B}$, The photomicrograph illustrates the tracer (biocytin, blue) injection site (enclosed by white dashed lines) in the MLR. Scale bar, $300 \mu \mathrm{m}$. C, The three micrographs were merged to show the three markers with dopamine in magenta, glutamate in green, and biocytin in blue. $\mathbf{D}-\mathbf{G}$, Transverse sections illustrate an example of triple labeling of PT cells positive for dopamine (magenta) and glutamate (green) that project to the MLR (blue). $\boldsymbol{H}-\boldsymbol{K}$, Magnification of the dashed rectangle in $\boldsymbol{D}-\boldsymbol{G}$. $\boldsymbol{D}, \boldsymbol{H}$, Dopamine-positive neurons (magenta) in the PT. $\boldsymbol{E}, \boldsymbol{I}$,
The swimming frequency was reduced at 40, 50, 60, 70, 80, 90, and $100 \%$ of maximal stimulation intensities $(p<0.05$ to $p<$ 0.001 against control, Student-Newman-Keuls test after a twoway ANOVA on ranks for repeated measures, $p<0.001)$ and graded control of locomotor frequency was still present with increasing intensities of PT stimulation ( sigmoid fit: $R^{2}=0.62, p<$ $0.0001, n=70$ trials pooled from 5 preparations). Altogether, these results suggest that glutamatergic inputs from the PT to the MLR are necessary for evoking locomotor output in a graded fashion, whereas the dopaminergic inputs amplify the descending glutamatergic command through $\mathrm{D}_{1}$ receptors without contributing to the rheostat-like effect.

\section{Discussion}

Results from the present study show in lamprey that the PT, a structure homologous to the mammalian $\mathrm{SNc}$, sends a descending glutamatergic input that controls MLR cell activity and swimming in a graded fashion. We found PT neurons labeled for both dopamine and glutamate that projected to the MLR, indicating a close interaction between these transmitters in the generation of the locomotor command. Blockade of $\mathrm{D}_{1}$ receptors in the MLR resulted in a reduced frequency of swimming movements without disrupting the graded control of locomotion by the PT, whereas blockade of glutamatergic receptors in the MLR nearly abolished locomotor output.

To our knowledge, results from the present study provide the first demonstration that the MLR can be activated incrementally by a higher brain region to control the speed of the locomotor movements. The substrate underlying this phenomenon consists of glutamatergic and dopaminergic inputs acting in parallel. We now show that the glutamatergic input is essential to elicit MLR activity and locomotion in a graded fashion, whereas the dopaminergic one provides additional excitation, but is not essential to evoke locomotion. In the presence of a $\mathrm{D}_{1}$ blocker, the relationship between stimulation intensity and swimming frequency was shifted to the right, indicating that a stronger stimulus was necessary to generate the same swimming frequency. This is consistent with our previous observation that dopamine application over the brainstem reduced the threshold of the current applied to the PT needed to elicit swimming (Ryczko et al., 2013). This suggests that $D_{1}$ activation either increases the strength of glutamatergic inputs to the MLR or increases MLR cell excitability through modulation of their intrinsic properties.

We found that some PT cells projecting to the MLR colocalize dopamine and glutamate. There is accumulating evidence that neurons with multiple transmitters are present in several neural circuits from lamprey to mammals (for review, see Granger et al., 2017). In zebrafish, catecholaminergic neurons were also found to coexpress either glutamate or GABA markers, including in the PT, where dopaminergic neurons preferentially use glutamate as a second transmitter (Filippi et al., 2014). In mammals, neurons co-storing dopamine and glutamate were found in the SNc and ventral tegmental area (Sulzer et al., 1998; Chuhma et al., 2004; Dal Bo et al., 2004; Kawano et al., 2006; Hnasko et al., 2010; Stuber et al., 2010; Fortin et al., 2012; for review, see Morales and Root, 2014). A future avenue would consist in determining

Glutamate-positive neurons (green) in the PT. $\boldsymbol{F}_{\text {, J }}$ Cells retrogradely labeled in the PT following biocytin (blue) injection in the MLR. $\boldsymbol{G}, \boldsymbol{K}$, Photomicrographs in $\boldsymbol{D}-\boldsymbol{F}$ and $\boldsymbol{H}-\boldsymbol{J}$ merged, respectively, to show the three markers. Arrowheads indicate examples of triple labeled cells. 


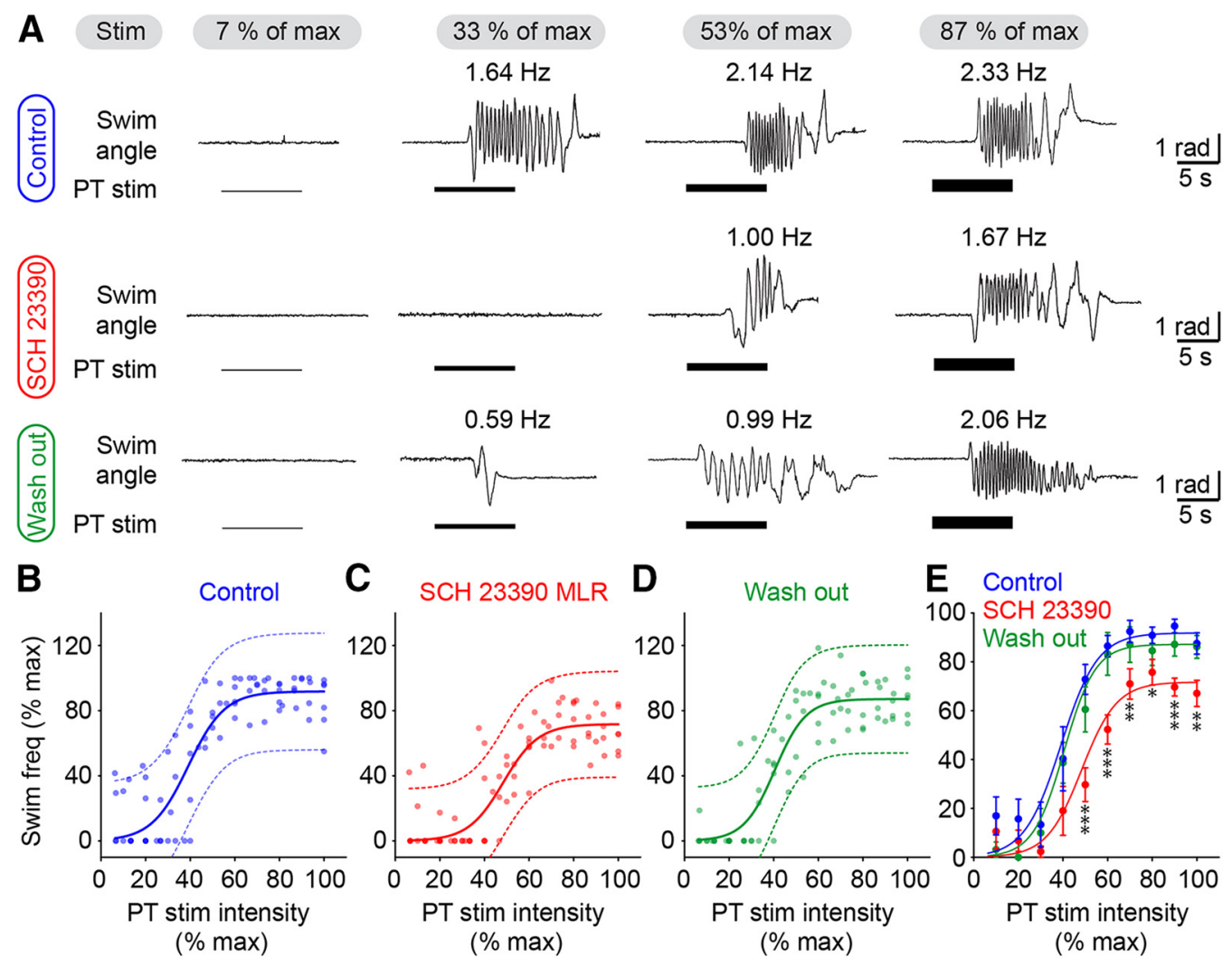

Figure 7. Effect of $D_{1}$ receptor blockade in the MLR on the graded control of swimming evoked by the PT. In a semi-intact preparation, the PT was stimulated electrically with increasing intensities. The $\mathrm{D}_{1}$ antagonist $\mathrm{SCH} 23390$ was microinjected in the MLR with a Picospritzer (pipette diameter $15-20 \mu \mathrm{m}$; pressure: 3- 4 psi; pulses: 20; duration $20-50 \mathrm{~ms}$ ). To quantify swimming frequency, the angular variations (radians) of the body curvature were measured over time. $A$, From left to right, incremental PT stimulation (1-15 $\mu \mathrm{A})$ elicited graded increase in swimming frequencies in control conditions (top), after microinjections of the $D_{1}$ receptor antagonist $S C H 23390$ in the $M L R$ (middle), and after a wash out period of $\sim 1 \mathrm{~h}$ (bottom). The average swimming frequency is indicated for each trial. $\boldsymbol{B}-\boldsymbol{D}$, Relationships for each condition between swimming frequency and PT stimulation intensity ( $1-16 \mu \mathrm{A}$; in each condition, $n=81$ trials pooled from 6 preparations). Data followed a sigmoidal function in control condition ( $\boldsymbol{B}$, blue solid line; $R^{2}=0.78, p<0.0001$, frequency range $\left.0.3-3.0 \mathrm{~Hz}\right)$, following microinjection of $0.4-1.5$ pmol of $S C H 23390(0.5 \mathrm{~mm})$ in the MLR $\left(\boldsymbol{C}\right.$, red solid line; $R^{2}=0.76, p<0.0001$, frequency range $0.3-2.4 \mathrm{~Hz}$ ) and after wash out ( $\boldsymbol{D}$, green solid line; $R^{2}=0.83, p<0.0001$, frequency range $0.5-2.9 \mathrm{~Hz}$ ). In each condition the dotted lines illustrate the $95 \%$ prediction intervals. Locomotor frequency and stimulation intensity were expressed as a percentage of their maximal values. $E$, Pooled data were binned as a function of stimulation intensity, with a bin size of $10 \%$. Normalized frequencies were compared for each bin using a two-way ANOVA on ranks. ${ }^{*} p<0.05$ against control, ${ }^{* *} p<0.01$ against control, ${ }^{* * *} p<0.001$ against control; Student-Newman-Keuls test after a two-way ANOVA on ranks for repeated measures, $p<0.001$. For convenience the sigmoid fits obtained from $\boldsymbol{B}-\boldsymbol{D}$ are illustrated for each condition.

whether the release of each transmitter is activity-dependent and targets different cell populations within the MLR.

The mechanisms underlying the interplay between dopaminergic and glutamatergic inputs from the primal SNc in the graded activation of MLR cells remain to be investigated. In mammals, $D_{1}$ receptor activation increases AMPA (Cepeda et al., 1993; HernándezEcheagaray et al., 2004; Tseng and O'Donnell, 2004; Han and Whelan, 2009) and NMDA-mediated responses (Cepeda et al., 1993; Tseng and O'Donnell, 2004). $\mathrm{D}_{2}$ receptors are also present in lampreys (Robertson et al., 2012; Ericsson et al., 2013; PérezFernández et al., 2014). In mammals $\mathrm{D}_{2}$ receptor activation decreases both AMPA- and NMDA-mediated components of glutamatergic responses (Cepeda et al., 1993; Hernández-Echeagaray et al., 2004; Tseng and O'Donnell, 2004). Dopamine could also modulate glutamatergic transmission presynaptically as shown in mammals (for review, see Tritsch and Sabatini, 2012) and lamprey spinal cord (Svensson et al., 2003a,b). There is also a possibility that dopamine acts directly on MLR cell intrinsic properties as shown in the lamprey striatum (Ericsson et al., 2013).

It is noteworthy that other forebrain regions send input to brainstem motor networks. The pallium (homologous to the mammalian cortex) sends projections to the MLR and reticulospinal neurons (Ocaña et al., 2015). Pallium stimulation elicits reticulospinal responses and sometimes elicits swimming in lam- preys (Ocaña et al., 2015), but whether incremental pallium activation can control MLR cell responses and locomotor movements is not known. In mammals, motor cortex stimulation is rather linked to voluntary modification of limb trajectory during ongoing locomotion (Bretzner and Drew, 2005). Moreover, another locomotor center, called the diencephalic locomotor region (considered to be equivalent to the subthalamic locomotor region in mammals), sends direct input to reticulospinal neurons (El Manira et al., 1997; Ménard and Grillner, 2008). The possibility that our present results might be explained by the recruitment of descending fibers originating from these two regions is unlikely, because the activation of the MLR was also obtained when stimulating the PT with local injections of glutamate, thus circumventing axonal recruitment. Future studies should seek to determine how these different inputs from supra-MLR regions are integrated by brainstem motor centers to shape motor output.

At the functional level, the dual inputs could tune the activity of MLR cells for the animal to appropriately approach targets or avoid threats, an essential function for survival. In this context, it is noteworthy that the olfactory bulb sends direct inputs to the PT (Derjean et al., 2010). Olfactory information could thus generate different levels of PT activity to control locomotor output in order for the animal to reach or avoid olfactory targets. Future 
studies should examine whether and how olfactory information controls the activity of cell populations in the PT.

The lamprey is considered as a blueprint of the vertebrate brain (Robertson et al., 2014), suggesting that the descending glutamatergic pathway from the SNc to brainstem locomotor networks reported here could be present in all vertebrates. In line with this possibility, we recently provided evidence that the descending dopaminergic pathway from the SNc to the MLR is conserved in amphibians, mammals, and likely humans (Ryczko et al., 2016b; for review, see Ryczko and Dubuc, 2017). Furthermore, the present study suggests that a dysfunction in the regulation of the interaction between glutamate and dopamine in the MLR could translate into abnormal activation of the locomotor system, and thus result in locomotor deficits such as those reported in Parkinson's disease and other locomotor disorders.

\section{References}

Abalo XM, Villar-Cheda B, Anadón R, Rodicio MC (2005) Development of the dopamine-immunoreactive system in the central nervous system of the sea lamprey. Brain Res Bull 66:560-564. CrossRef Medline

Albin RL, Young AB, Penney JB (1989) The functional anatomy of basal ganglia disorders. Trends Neurosci 12:366-375. CrossRef Medline

Bachmann LC, Matis A, Lindau NT, Felder P, Gullo M, Schwab ME (2013) Deep brain stimulation of the midbrain locomotor region improves paretic hindlimb function after spinal cord injury in rats. Sci Transl Med 5:208ra146. CrossRef Medline

Barreiro-Iglesias A, Villar-Cerviño V, Villar-Cheda B, Anadón R, Rodicio MC (2008) Neurochemical characterization of sea lamprey taste buds and afferent gustatory fibers: presence of serotonin, calretinin, and CGRP immunoreactivity in taste bud bi-ciliated cells of the earliest vertebrates. J Comp Neurol 511:438-453. CrossRef Medline

Bernau NA, Puzdrowski RL, Leonard RB (1991) Identification of the midbrain locomotor region and its relation to descending locomotor pathways in the Atlantic stingray, Dasyatis sabina. Brain Res 557:83-94. CrossRef Medline

Bretzner F, Brownstone RM (2013) Lhx3-Chx10 reticulospinal neurons in locomotor circuits. J Neurosci 33:14681-14692. CrossRef Medline

Bretzner F, Drew T (2005) Contribution of the motor cortex to the structure and the timing of hindlimb locomotion in the cat: a microstimulation study. J Neurophysiol 94:657-672. CrossRef Medline

Brocard F, Dubuc R (2003) Differential contribution of reticulospinal cells to the control of locomotion induced by the mesencephalic locomotor region. J Neurophysiol 90:1714-1727. CrossRef Medline

Brocard F, Ryczko D, Fénelon K, Hatem R, Gonzales D, Auclair F, Dubuc R (2010) The transformation of a unilateral locomotor command into a symmetrical bilateral activation in the brainstem. J Neurosci 30:523-533. CrossRef Medline

Buchanan JT, Grillner S (1987) Newly identified "glutamate interneurons" and their role in locomotion in the lamprey spinal cord. Science 236:312314. CrossRef Medline

Cabelguen JM, Bourcier-Lucas C, Dubuc R (2003) Bimodal locomotion elicited by electrical stimulation of the midbrain in the salamander Notophthalmus viridescens. J Neurosci 23:2434-2439. Medline

Cepeda C, Buchwald NA, Levine MS (1993) Neuromodulatory actions of dopamine in the neostriatum are dependent upon the excitatory amino acid receptor subtypes activated. Proc Natl Acad Sci U S A 90:9576-9580. CrossRef Medline

Chuhma N, Zhang H, Masson J, Zhuang X, Sulzer D, Hen R, Rayport S (2004) Dopamine neurons mediate a fast excitatory signal via their glutamatergic synapses. J Neurosci 24:972-981. CrossRef Medline

Dal Bo G, St-Gelais F, Danik M, Williams S, Cotton M, Trudeau LE (2004) Dopamine neurons in culture express VGLUT2 explaining their capacity to release glutamate at synapses in addition to dopamine. J Neurochem 88:1398-1405. CrossRef Medline

Derjean D, Moussaddy A, Atallah E, St-Pierre M, Auclair F, Chang S, Ren X, Zielinski B, Dubuc R (2010) A novel neural substrate for the transformation of olfactory inputs into motor output. PLoS Biol 8:e1000567. CrossRef Medline

Eidelberg E, Walden JG, Nguyen LH (1981) Locomotor control in macaque monkeys. Brain 104:647-663. CrossRef Medline

El Manira A, Pombal MA, Grillner S (1997) Diencephalic projection to re- ticulospinal neurons involved in the initiation of locomotion in adult lampreys Lampetra fluviatilis. J Comp Neurol 389:603-616. CrossRef Medline

Ericsson J, Stephenson-Jones M, Pérez-Fernández J, Robertson B, Silberberg G, Grillner S (2013) Dopamine differentially modulates the excitability of striatal neurons of the direct and indirect pathways in lamprey. J Neurosci 33:8045-8054. CrossRef Medline

Fernández-López B, Villar-Cerviño V, Valle-Maroto SM, Barreiro-Iglesias A, Anadón R, Rodicio MC (2012) The glutamatergic neurons in the spinal cord of the sea lamprey: an in situ hybridization and immunohistochemical study. PloS One 7:e47898. CrossRef Medline

Filippi A, Mueller T, Driever W (2014) vglut2 and gad expression reveal distinct patterns of dual GABAergic versus glutamatergic cotransmitter phenotypes of dopaminergic and noradrenergic neurons in the zebrafish brain. J Comp Neurol 522:2019-2037. CrossRef Medline

Fortin GM, Bourque MJ, Mendez JA, Leo D, Nordenankar K, Birgner C, Arvidsson E, Rymar VV, Bérubé-Carrière N, Claveau AM, Descarries L, Sadikot AF, Wallén-Mackenzie Å, Trudeau LÉ (2012) Glutamate corelease promotes growth and survival of midbrain dopamine neurons. J Neurosci 32:17477-17491. CrossRef Medline

Garcia-Rill E, Skinner RD (1987a) The mesencephalic locomotor region: I. Activation of a medullary projection site. Brain Res 411:1-12. CrossRef Medline

Garcia-Rill E, Skinner RD (1987b) The mesencephalic locomotor region: II. Projections to reticulospinal neurons. Brain Res 411:13-20. CrossRef Medline

Garcia-Rill E, Houser CR, Skinner RD, Smith W, Woodward DJ (1987) Locomotion-inducing sites in the vicinity of the pedunculopontine nucleus. Brain Res Bull 18:731-738. CrossRef Medline

Gariépy JF, Missaghi K, Chevallier S, Chartré S, Robert M, Auclair F, Lund JP, Dubuc R (2012a) Specific neural substrate linking respiration to locomotion. Proc Natl Acad Sci U S A 109:E84-E92. CrossRef Medline

Gariépy JF, Missaghi K, Chartré S, Robert M, Auclair F, Dubuc R (2012b) Bilateral connectivity in the brainstem respiratory networks of lampreys. J Comp Neurol 520:1442-1456. CrossRef Medline

Goetz L, Piallat B, Bhattacharjee M, Mathieu H, David O, Chabardès S (2016) On the role of the pedunculopontine nucleus and mesencephalic reticular formation in locomotion in nonhuman primates. J Neurosci 36:4917-4929. CrossRef Medline

Granger AJ, Wallace ML, Sabatini BL (2017) Multi-transmitter neurons in the mammalian central nervous system. Curr Opin Neurobiol 45:85-91. CrossRef Medline

Grillner S, Robertson B (2016) The basal ganglia over 500 million years. Curr Biol 26:R1088-R1100. CrossRef Medline

Grillner S, Robertson B, Stephenson-Jones M (2013) The evolutionary origin of the vertebrate basal ganglia and its role in action selection. J Physiol 591:5425-5431. CrossRef Medline

Han P, Whelan PJ (2009) Modulation of AMPA currents by $\mathrm{D}_{1}$-like but not $\mathrm{D}_{2}$-like receptors in spinal motoneurons. Neuroscience 158:1699-1707. CrossRef Medline

Hernández-Echeagaray E, Starling AJ, Cepeda C, Levine MS (2004) Modulation of AMPA currents by $\mathrm{D} 2$ dopamine receptors in striatal medium-sized spiny neurons: are dendrites necessary? Eur J Neurosci 19:2455-2463. CrossRef Medline

Hnasko TS, Chuhma N, Zhang H, Goh GY, Sulzer D, Palmiter RD, Rayport S, Edwards RH (2010) Vesicular glutamate transport promotes dopamine storage and glutamate corelease in vivo. Neuron 65:643-656. CrossRef Medline

Islam SS, Zelenin PV (2008) Modifications of locomotor pattern underlying escape behavior in the lamprey. J Neurophysiol 99:297-307. Medline

Juvin L, Grätsch S, Trillaud-Doppia E, Gariépy JF, Büschges A, Dubuc R (2016) A specific population of reticulospinal neurons controls the termination of locomotion. Cell Rep 15:2377-2386. CrossRef Medline

Karachi C, Grabli D, Bernard FA, Tandé D, Wattiez N, Belaid H, Bardinet E, Prigent A, Nothacker HP, Hunot S, Hartmann A, Lehéricy S, Hirsch EC, François C (2010) Cholinergic mesencephalic neurons are involved in gait and postural disorders in Parkinson disease. J Clin Invest 120:27452754. CrossRef Medline

Kawano M, Kawasaki A, Sakata-Haga H, Fukui Y, Kawano H, Nogami H, Hisano S (2006) Particular subpopulations of midbrain and hypothalamic dopamine neurons express vesicular glutamate transporter 2 in the rat brain. J Comp Neurol 498:581-592. CrossRef Medline 
Kravitz AV, Freeze BS, Parker PR, Kay K, Thwin MT, Deisseroth K, Kreitzer AC (2010) Regulation of parkinsonian motor behaviours by optogenetic control of basal ganglia circuitry. Nature 466:622-626. CrossRef Medline

Lee AM, Hoy JL, Bonci A, Wilbrecht L, Stryker MP, Niell CM (2014) Identification of a brainstem circuit regulating visual cortical state in parallel with locomotion. Neuron 83:455-466. CrossRef Medline

Le Ray D, Brocard F, Bourcier-Lucas C, Auclair F, Lafaille P, Dubuc R (2003) Nicotinic activation of reticulospinal cells involved in the control of swimming in lampreys. Eur J Neurosci 17:137-148. CrossRef Medline

Marlinsky VV, Voitenko LP (1991) The effect of procaine injection into the medullary reticular formation on forelimb muscle activity evoked by mesencephalic locomotor region and vestibular stimulation in the decerebrated guinea-pig. Neuroscience 45:753-759. CrossRef Medline

Ménard A, Grillner S (2008) Diencephalic locomotor region in the lamprey: afferents and efferent control. J Neurophysiol 100:1343-1353. CrossRef Medline

Ménard A, Auclair F, Bourcier-Lucas C, Grillner S, Dubuc R (2007) Descending GABAergic projections to the mesencephalic locomotor region in the lamprey Petromyzon marinus. J Comp Neurol 501:260-273. CrossRef Medline

Morales M, Root DH (2014) Glutamate neurons within the midbrain dopamine regions. Neuroscience 282:60-68. CrossRef Medline

Musienko PE, Zelenin PV, Lyalka VF, Orlovsky GN, Deliagina TG (2008) Postural performance in decerebrated rabbit. Behav Brain Res 190:124134. CrossRef Medline

Musienko PE, Zelenin PV, Lyalka VF, Gerasimenko YP, Orlovsky GN, Deliagina TG (2012) Spinal and supraspinal control of the direction of stepping during locomotion. J Neurosci 32:17442-17453. CrossRef Medline

Noga BR, Kriellaars DJ, Jordan LM (1991) The effect of selective brainstem or spinal cord lesions on treadmill locomotion evoked by stimulation of the mesencephalic or pontomedullary locomotor regions. J Neurosci 11: 1691-1700. Medline

Ocaña FM, Suryanarayana SM, Saitoh K, Kardamakis AA, Capantini L, Robertson B, Grillner S (2015) The lamprey pallium provides a blueprint of the mammalian motor projections from cortex. Curr Biol 25:413-423. CrossRef Medline

Orlovskii GN (1970) Work of reticulo-spinal neurons during locomotion (in Russian). Biofizika 15:728-737. Medline

Pérez-Fernández J, Stephenson-Jones M, Suryanarayana SM, Robertson B, Grillner S (2014) Evolutionarily conserved organization of the dopaminergic system in lamprey: SNc/VTA afferent and efferent connectivity and D2 receptor expression. J Comp Neurol 522:3775-3794. CrossRef Medline

Pierre J, Mahouche M, Suderevskaya EI, Repérant J, Ward R (1997) Immunocytochemical localization of dopamine and its synthetic enzymes in the central nervous system of the lamprey Lampetra fluviatilis. J Comp Neurol 380:119-135. CrossRef Medline

Pombal MA, El Manira A, Grillner S (1997) Afferents of the lamprey striatum with special reference to the dopaminergic system: a combined tracing and immunohistochemical study. J Comp Neurol 386:71-91. CrossRef Medline

Redgrave P, Prescott TJ, Gurney K (1999) The basal ganglia: a vertebrate solution to the selection problem? Neuroscience 89:1009-1023. CrossRef Medline

Robertson B, Huerta-Ocampo I, Ericsson J, Stephenson-Jones M, PérezFernández J, Bolam JP, Diaz-Heijtz R, Grillner S (2012) The dopamine D2 receptor gene in lamprey, its expression in the striatum and cellular effects of D2 receptor activation. PloS One 7:e35642. CrossRef Medline

Robertson B, Kardamakis A, Capantini L, Pérez-Fernández J, Suryanarayana SM, Wallén P, Stephenson-Jones M, Grillner S (2014) The lamprey blueprint of the mammalian nervous system. Prog Brain Res 212:337349. CrossRef Medline

Roseberry TK, Lee AM, Lalive AL, Wilbrecht L, Bonci A, Kreitzer AC (2016) Cell-type-specific control of brainstem locomotor circuits by basal ganglia. Cell 164:526-537. CrossRef Medline

Rovainen CM (1967) Physiological and anatomical studies on large neurons of central nervous system of the sea lamprey (Petromyzon marinus): I. Müller and Mauthner cells. J Neurophysiol 30:1000-1023. Medline

Ryczko D, Dubuc R (2013) The multifunctional mesencephalic locomotor region. Curr Pharm Des 19:4448-4470. CrossRef Medline

Ryczko D, Grätsch S, Auclair F, Dubé C, Bergeron S, Alpert MH, Cone JJ, Roitman MF, Alford S, Dubuc R (2013) Forebrain dopamine neurons project down to a brainstem region controlling locomotion. Proc Natl Acad Sci U S A 110:E3235-3242. CrossRef Medline

Ryczko D, Auclair F, Cabelguen JM, Dubuc R (2016a) The mesencephalic locomotor region sends a bilateral glutamatergic drive to hindbrain reticulospinal neurons in a tetrapod. J Comp Neurol 524:1361-1383. CrossRef Medline

Ryczko D, Cone JJ, Alpert MH, Goetz L, Auclair F, Dubé C, Parent M, Roitman MF, Alford S, Dubuc R (2016b) A descending dopamine pathway conserved from basal vertebrates to mammals. Proc Natl Acad Sci U S A 113:E2440-2449. CrossRef Medline

Ryczko D, Dubuc R (2017) Dopamine and the brainstem locomotor networks: from lamprey to human. Front Neurosci 11:295. CrossRef Medline

Shik ML, Severin FV, Orlovskiü GN (1966) Control of walking and running by means of electric stimulation of the midbrain (in Russian). Biofizika 11:659-666. Medline

Sholomenko GN, Funk GD, Steeves JD (1991) Avian locomotion activated by brainstem infusion of neurotransmitter agonists and antagonists: II. $\gamma$-Aminobutyric acid. Exp Brain Res 85:674-681. CrossRef Medline

Sirota MG, Di Prisco GV, Dubuc R (2000) Stimulation of the mesencephalic locomotor region elicits controlled swimming in semi-intact lampreys. Eur J Neurosci 12:4081-4092. CrossRef Medline

Steeves JD, Jordan LM (1980) Localization of a descending pathway in the spinal cord which is necessary for controlled treadmill locomotion. Neurosci Lett 20:283-288. CrossRef Medline

Stephenson-Jones M, Samuelsson E, Ericsson J, Robertson B, Grillner S (2011) Evolutionary conservation of the basal ganglia as a common vertebrate mechanism for action selection. Curr Biol 21:1081-1091. CrossRef Medline

Stephenson-Jones M, Ericsson J, Robertson B, Grillner S (2012) Evolution of the basal ganglia: dual-output pathways conserved throughout vertebrate phylogeny. J Comp Neurol 520:2957-2973. CrossRef Medline

Stuber GD, Hnasko TS, Britt JP, Edwards RH, Bonci A (2010) Dopaminergic terminals in the nucleus accumbens but not the dorsal striatum corelease glutamate. J Neurosci 30:8229-8233. CrossRef Medline

Sulzer D, Joyce MP, Lin L, Geldwert D, Haber SN, Hattori T, Rayport S (1998) Dopamine neurons make glutamatergic synapses in vitro. J Neurosci 18:4588-4602. Medline

Svensson E, Wikström MA, Hill RH, Grillner S (2003a) Endogenous and exogenous dopamine presynaptically inhibits glutamatergic reticulospinal transmission via an action of D2-receptors on N-type Ca2 + channels. Eur J Neurosci 17:447-454. CrossRef Medline

Svensson E, Woolley J, Wikström M, Grillner S (2003b) Endogenous dopaminergic modulation of the lamprey spinal locomotor network. Brain Res 970:1-8. CrossRef Medline

Takakusaki K, Habaguchi T, Ohtinata-Sugimoto J, Saitoh K, Sakamoto T (2003) Basal ganglia efferents to the brainstem centers controlling postural muscle tone and locomotion: a new concept for understanding motor disorders in basal ganglia dysfunction. Neuroscience 119:293-308. CrossRef Medline

Tritsch NX, Sabatini BL (2012) Dopaminergic modulation of synaptic transmission in cortex and striatum. Neuron 76:33-50. CrossRef Medline

Tseng KY, O'Donnell P (2004) Dopamine-glutamate interactions controlling prefrontal cortical pyramidal cell excitability involve multiple signaling mechanisms. J Neurosci 24:5131-5139. CrossRef Medline

Villar-Cerviño V, Abalo XM, Villar-Cheda B, Meléndez-Ferro M, PérezCostas E, Holstein GR, Martinelli GP, Rodicio MC, Anadón R (2006) Presence of glutamate, glycine, and gamma-aminobutyric acid in the retina of the larval sea lamprey: comparative immunohistochemical study of classical neurotransmitters in larval and postmetamorphic retinas. J Comp Neurol 499:810-827. CrossRef Medline

Villar-Cerviño V, Barreiro-Iglesias A, Mazan S, Rodicio MC, Anadón R (2011) Glutamatergic neuronal populations in the forebrain of the sea lamprey, Petromyzon marinus: an in situ hybridization and immunocytochemical study. J Comp Neurol 519:1712-1735. CrossRef Medline

Villar-Cerviño V, Barreiro-Iglesias A, Fernández-López B, Mazan S, Rodicio MC, Anadón R (2013) Glutamatergic neuronal populations in the brainstem of the sea lamprey, Petromyzon marinus: an in situ hybridization and immunocytochemical study. J Comp Neurol 521:522-557. CrossRef Medline 